\title{
Article
}

\section{Identity of the Most and Least Active Sites for Activation of the Pathway for CO2 Formation from the Electro- oxidation of Methanol and Ethanol on Platinum}

Manuel J. S. Farias, William Cheuquepán, Auro A. Tanaka, and Juan Miguel Feliu ACS Catal., Just Accepted Manuscript • DOI: 10.1021/acscatal.9b04275 • Publication Date (Web): 28 Nov 2019 Downloaded from pubs.acs.org on November 28, 2019

\section{Just Accepted}

"Just Accepted" manuscripts have been peer-reviewed and accepted for publication. They are posted online prior to technical editing, formatting for publication and author proofing. The American Chemical Society provides "Just Accepted" as a service to the research community to expedite the dissemination of scientific material as soon as possible after acceptance. "Just Accepted" manuscripts appear in full in PDF format accompanied by an HTML abstract. "Just Accepted" manuscripts have been fully peer reviewed, but should not be considered the official version of record. They are citable by the Digital Object Identifier (DOI®). "Just Accepted" is an optional service offered to authors. Therefore, the "Just Accepted" Web site may not include all articles that will be published in the journal. After a manuscript is technically edited and formatted, it will be removed from the "Just Accepted" Web site and published as an ASAP article. Note that technical editing may introduce minor changes to the manuscript text and/or graphics which could affect content, and all legal disclaimers and ethical guidelines that apply to the journal pertain. ACS cannot be held responsible for errors or consequences arising from the use of information contained in these "Just Accepted" manuscripts. 


\begin{abstract}
In the field of the catalysis on solid surfaces, discrimination of the site-specific chemistry taking place on surfaces consisting of multiple types of sites is challenging, especially at electrified solid/liquid interfaces. In this study, site-specific chemical labeling on Pt stepped surfaces was achieved by attaching the ${ }^{13} \mathrm{CO}$ species exclusively on the top side of the (110) steps, while maintaining all the (111) sites available. The catalysts were then employed in a spectro-electrochemical study of the electro-oxidation of methanol and ethanol. The onset potentials for the formation of ${ }^{13} \mathrm{CO}_{2}$ and ${ }^{12} \mathrm{CO}_{2}$ revealed the existence of two channels of carbon dioxide formation, separated by about $0.22 \mathrm{~V}$, on the same Pt surface. The active sites with lower over-potential requirement (or lower energy input) for activation of the reaction pathway of $\mathrm{CO}_{2}$ formation resided on the (111) terraces. On the other hand, the active sites with higher over-potential requirement (or higher energy input) for activation of the reaction pathway for electro-oxidation of ${ }^{13} \mathrm{CO}_{\text {ads }}$ species to ${ }^{13} \mathrm{CO}_{2}$ were at the top of the (110) steps. The findings revealed the identities of the most active sites and least active sites involved in the formation of $\mathrm{CO}_{2}$ during the electro-oxidation of alcohols. On Pt surfaces, the complex interplay involving the steps on the surface favors activation of the pathways for $\mathrm{CO}_{\mathrm{ads}}$ oxidation on the (111) terraces, rather than promoting reaction steps directly on the steps themselves.
\end{abstract}

Keywords: Electrocatalysis, platinum, structure sensitivity, step sites, terrace sites, active sites.

*Corresponding author: manueljsfarias@gmail.com

(Manuel J. S. Farias). Phone: +55 9833018246. 


\section{Introduction}

The concepts of active sites and most active sites are intriguing in the field of catalysis on solid surfaces. Revealing their identities has proved challenging, but is necessary for understanding the factors underlying the catalysis phenomenon, as well as being of paramount importance for the design of active, selective, and durable catalysts. ${ }^{1-4}$ In this regard, the surfaces of real catalysts are heterogeneous at the molecular scale, with the topmost surface consisting of steps/defects, terraces, holes, and so on, ${ }^{5}$ and these different locations on the surface have different chemical environments. ${ }^{6}$ Historically, a systematic approach concerning the identities of the catalytic active sites on solid surfaces was published by Taylor, ${ }^{7}$ in a review paper in 1925 . According to him, low coordination atoms on the surface act, by themselves, as active sites. Today, we know that this affirmation is not entirely correct for any and all reactions on solid surfaces. The concepts of most active sites and less active sites imply the requirement for lower and higher inputs of energy, respectively, for activation of the pathways and establishment of a reaction. It should be noted that in describing catalytic activity, the concept of active sites is linked to a particular reaction. In the field of electrocatalysis, an especially useful reaction probe that can be used to study the catalytic properties of materials is the electro-oxidation reaction of $\mathrm{CO}$. The reason is that on a Pt catalyst, this reaction is surface structure sensitive, ${ }^{8}$ with $\mathrm{CO}_{2}$ being the single reaction product. In addition, adsorbed $\mathrm{CO}\left(\mathrm{CO}_{\mathrm{ads}}\right)$ can appear as an intermediate species during the pathway of electro-oxidation of alcohols, such as methanol and ethanol, to $\mathrm{CO}_{2} \cdot{ }^{9}$ These two alcohols are potential candidates for use as fuels in direct alcohol fuel cells, ${ }^{10-12}$ but the sluggish kinetics of their electro-oxidation on the anode limits the efficiency of these energy conversion devices. ${ }^{13,14}$ One reason for the slow kinetics of alcohol electro-oxidation toward $\mathrm{CO}_{2}$ is related to the accumulation of $\mathrm{CO}_{\mathrm{ads}}$ on the surface, which acts as a catalytic poison. ${ }^{13}$ Therefore, study of the nature of the reaction pathway for $\mathrm{CO}_{2}$ formation is needed in order to be able to understand the origins of the high potentials required for the oxidation of $\mathrm{CO}_{\mathrm{ads}}$ in the mechanism of electro-oxidation of alcohols. In particular, deciphering the characteristics of the most active sites is an outstanding issue in catalysis on solid surfaces and needs to be investigated.

On Pt electrodes, the reactions of electro-oxidation of alcohols are inefficient in terms of $\mathrm{CO}_{2}$ production. For instance, the electro-oxidation reaction of ethanol, depending on its concentration, yields a fraction of $\mathrm{CO}_{2}$ that varies from about 0.5 to $7 \% .^{15}$ The main reaction 
products are acetic acid and acetaldehyde, ${ }^{16}$ representing low exploitation of the full Faradaic power of ethanol as a fuel. However, the ethanol electro-oxidation reaction is surface structure sensitive, ${ }^{17}$ so one way to selectively tune the reaction consists of changing the structure of the topmost surface (and/or sub-surface). The $\operatorname{Pt}(111)$ surface of the basal plane of platinum is less efficient in C-C bond splitting, so there is less conversion of $\mathrm{CO}_{\mathrm{ads}}$ to $\mathrm{CO}_{2} \cdot{ }^{18}$ The introduction of defects in the (111) plane can, to some extent, increase the overall rate of ethanol electro-oxidation. ${ }^{19,20}$ In a computational chemistry study, ${ }^{21}$ the low $\mathrm{CO}_{2}$ efficiency was interpreted in terms of restricted removal of $\mathrm{CO}_{a d s}$, rather than $\mathrm{C}-\mathrm{C}$ splitting. In the case of methanol, the electro-oxidation reaction on Pt also behaves as being surface structure sensitive. ${ }^{22,23}$ The $\mathrm{CO}_{2}$ production efficiency was found to vary from $\sim 20 \%$ to $\sim 32 \%$ as the potential was increased from $0.6 \mathrm{~V}_{\mathrm{RHE}}$ to $0.8 \mathrm{~V}_{\mathrm{RHE}}{ }^{24}$ On the cyanide-Pt(111) modified electrode, it has been reported that at least three contiguous $\mathrm{Pt}$ atoms are required for dissociation of the methanol molecule towards $\mathrm{CO}_{\mathrm{ads}} .{ }^{25}$ Previous studies employing $\mathrm{Pt}(111)$ vicinal surfaces showed that the (110) steps are highly active toward dissociating methanol and yielding $\mathrm{CO}_{\mathrm{ads}},{ }^{26}$ but nothing is known about the other step of the forward reaction, which is the conversion of $\mathrm{CO}_{\mathrm{ads}}$ to $\mathrm{CO}_{2}$. To further complicate the issue, experiments have shown that the formation of $\mathrm{CO}_{2}$ from methanol electro-oxidation by the non- $\mathrm{CO}_{\text {ads }}$ pathway only starts at a potential of about $0.7 \mathrm{~V}_{\mathrm{RHE}}$, which is higher than the potential at which $\mathrm{CO}_{2}$ is formed in the $\mathrm{CO}_{\text {ads }}$ pathway. ${ }^{25}$ Due to the heterogeneity of the sites on the catalyst surfaces, it is not plausible that the step and terrace sites present similar catalytic activity, given the structure sensitive nature of the reaction. Therefore, in comparison to non- $\mathrm{CO}_{\mathrm{ads}}$ pathways, a fundamental issue in heterogeneous electrocatalysis is to investigate the different abilities (meaning energy inputs) that different sites on the catalyst surface present for activation of the pathways of $\mathrm{CO}_{2}$ formation from the $\mathrm{CO}_{\text {ads }}$ species derived from alcohols.

Concerning the geometric configuration of the atoms on the topmost surface, the site heterogeneity on catalyst surfaces can, in principle, be spatially resolved by imaging the surface at the atomic level. ${ }^{27-29}$ However, from the chemistry viewpoint, the identification of active sites is not an easy task. In the field of electrocatalysis, it often involves introducing specific types of sites on a basal plane, such as locating crystalline (or even ill-defined) steps over the (111) terraces. In this case, the inhibition or increase of catalytic activity is monitored without distinguishing the chemistry at specific electrocatalytic sites. ${ }^{8,19}$ Another way to probe the site-specific catalytic activity is based on blockage of certain types of sites, such as 
steps/defects, by attaching "non-reactive" foreign atoms on them, leaving the rest of the sites free to interact with the reactive species. ${ }^{30-33}$ In either case, the active site is indirectly identified by means of a notable effect observed in a particular catalytic property, which could be the rate and/or selectivity of a reaction. Although these two procedures described above can be strongly chemically intuitive, they consider that the density of the active sites, or the overall activity, results from a simple linear combination among different facets at the surface. Furthermore, they also consider that the "non-reactive" foreign atoms do not affect the chemistry at neighboring sites. As a matter of fact, the use of foreign atoms to block steps/defects on a substrate originates new steps and neighborhoods that frequently have distinct physical and chemical properties. This principle has been used to explore the active sites in the electro-oxidation of CO on stepped Pt single crystal surfaces selectively modified by foreign atoms. ${ }^{34,35}$ Active sites on solid catalyst surfaces have also been studied by in situ electrochemical STM (scanning tunneling microscopy), in which, under operation condition, the relative level of noise of the tunneling current changes as the STM tip passes over highly active sites, in comparison to sites with low activity. ${ }^{36}$ This innovative in situ STM methodology has only been successful for fast reactions or reactions near diffusional control. An additional consideration is that the nanometer scale of resolution of active sites is scattered over the widths of many atoms. This means that the ability to differentiate the activity at the upper sides of the steps and their counterparts has not been achieved. In a general way, the chemistry at different active sites is complex, because the active sites do not correspond exactly to the situation in which there is mere enriching of a geometric configuration of atoms on the surface, as highlighted in studies of catalysis at the solid/gas interface. ${ }^{37}$ Indeed, the determination of active sites has not considered the influence of steps/defects on their neighbors. Therefore, in order to probe the chemistry at different active sites on a catalyst with heterogeneous sites, an ideal experiment should consist of chemically marking specific electrocatalytic sites, without affecting the chemistry at the neighboring sites, and then monitoring the chemistry at the chemically marked sites, as well as at the rest of the sites. We have developed an experimental strategy that perfectly fulfills this ideal condition and works extremely well at the electrified metal/solution interface, even with sluggish reaction kinetics. The principle concept in this strategy is to use, as a site-specific marking agent, a chemical species that must be naturally formed during the overall mechanism of the reaction in question. This ensures that neighboring sites are not disturbed as a result of the marking of 


\section{Experimental Section}

\subsection{Electrodes and Electrolyte}

The Pt single crystals used as working electrodes were two bead-type $\operatorname{Pt}(332)$ and $\operatorname{Pt}(665)$ electrodes (with oriented areas about $22 \mathrm{~mm}^{-2}$ ). The nominal structures of the $\mathrm{Pt}(332)$ and $\operatorname{Pt}(665)$ surfaces corresponded to 5 atoms-wide, and 11 atoms-wide (111) terraces, respectively, which were periodically interrupted by (110) monoatomic steps. According to the Lang-Joyner-Somorjai model, ${ }^{39}$ these two surfaces belong to the $\mathrm{Pt}(\mathrm{s})-[(n-1)(111) \times(110)]$ series and can be represented individually as follows:

$$
\begin{gathered}
\operatorname{Pt}(332) \equiv \operatorname{Pt}(\mathrm{s})-[5(111) \times(110)], n-1=5 \\
\operatorname{Pt}(665) \equiv \operatorname{Pt}(\mathrm{s})-[11(111) \times(110)], n-1=11
\end{gathered}
$$

The protocol for preparing these electrodes followed the well-known Clavilier procedure. ${ }^{40}$ The counter electrode used was a Pt wire, the reference electrode was a reversible hydrogen electrode (RHE), and all the potentials were referred to the RHE scale. The electrode potentials were controlled using a waveform generator (Model 175, EG\&G PARC), a potentiostat (Model 551, Amel), and a digital recorder (Model ED 401, eDAC).

The electrolytic solution was $0.1 \mathrm{M} \mathrm{HClO}_{4}(70 \%$, Aldrich), prepared in ultrapure water (18.2 $\mathrm{M} \Omega \mathrm{cm}$ ). Prior to the experiments, the electrolytic solutions were deoxygenated by bubbling with $\operatorname{Ar}$ (N50, Alpha Gaz). The other gases used were CO (N47, Alpha Gaz) and ${ }^{13} \mathrm{CO}$ (99\%, Cambridge Isotope Laboratories, Inc.). Absolute methanol and absolute ethanol were used (both 99.9\%, Merck). 
All the experiments were carried out at room temperature in the laboratory $(25 \pm 1.0$ $\left.{ }^{\circ} \mathrm{C}\right)$.

\subsection{Spectro-Electrochemical Experiments}

In situ FTIR spectra were recorded using a Nicolet 8700 spectrometer equipped with an MCT detector cooled with liquid $\mathrm{N}_{2}$. The spectro-electrochemical cell used has been described elsewhere. ${ }^{41}$ The cell configuration included a prismatic $\mathrm{CaF}_{2}$ window fitted at an angle of $60^{\circ}$. The in situ FTIR spectra were recorded as the average of 200 interferograms, with resolution of $8 \mathrm{~cm}^{-1}$, requiring about 2 minutes for the acquisition and storage of each spectrum. The series of spectra for each spectro-electrochemical experiment were recorded from 0.060 to $0.800 \mathrm{~V}$ (in intervals of $25 \mathrm{mV}$ ). The spectra were presented in terms of absorbance units:

$$
A=-\log \left(\frac{R_{0}-R_{s}}{R_{0}}\right) \text { versus } v / \mathrm{cm}^{-1}
$$

where $R_{0}$ is the single beam reflectance spectrum at the reference potential and $R_{S}$ is the single beam reflectance spectrum at the sampling potential. In the spectra, the bands pointing up refer to the species whose concentration grows into a thin layer, while the bands pointing down refer to the species whose concentration diminishes in the thin layer. For the detection of both dissolved species in the thin layer and species on the Pt crystal surface, $p$-polarized radiation was employed, in accordance with the surface selection rule. ${ }^{41}$

\section{Results}

\subsection{Fingerprints of Step and Terrace Sites on Pt Surfaces as Probed by Hydrogen Adsorption/Desorption and Adsorption of CO on the Top of the Steps}

Figure 1 shows cyclic voltammograms of the $\mathrm{Pt}(332)$ and $\mathrm{Pt}(665)$ single crystal surfaces in contact with $0.1 \mathrm{M} \mathrm{HClO}_{4}$ solution. Also shown is a hard sphere model of a stepped surface, indicating the presence of different catalytic sites on the surface. The data shown by the orange line correspond to the condition where the top of the steps at the Pt surfaces were selectively occupied by ${ }^{13} \mathrm{CO}$ species. Considering the Pt voltammograms shown by the blue lines in Figure 1, the features of the voltammograms for the $\operatorname{Pt}(332)$ and $\operatorname{Pt}(665)$ surfaces indicate high quality of the oriented surfaces and solution cleanness. For these two stepped Pt surfaces, at potentials below $\sim 0.25 \mathrm{~V}_{\mathrm{RHE}}$ (which corresponds approximately to potential of zero total charge ${ }^{42}$ ), the interfacial processes were dominated by the adsorption/desorption 
of hydrogen, that is the reversible discharge of the proton to form adsorbed hydrogen, together with the reverse reaction, which occurred at all types of available Pt sites. ${ }^{43}$ Disregarding the adsorption of anions and the participation of the interfacial water in the overall (electro)chemical process, the hydrogen adsorption/desorption reactions can be represented as follows:

$$
\mathrm{H}_{\mathrm{ads}} \rightleftarrows \mathrm{H}^{+}+e^{-}+{ }^{*} \text { available Pt sites }
$$

This electrochemical reaction is characterized as being fast, surface-limited, and strongly sensitive to the structure of the Pt catalytic sites. These reactions are so surface structure sensitive that a change in the surface of the Pt causes a noticeable change in the voltammetric behavior in the hydrogen region. Reaction (2) occurring at the top side of the steps (see site assignments in Figure 1) is associated with a pair of features at a potential of about $\sim 0.127 \mathrm{~V}_{\mathrm{RHE}}$ for a solution $\mathrm{pH}$ about $1{ }^{44}$, reflecting the reversible character of the reaction. These features result from the reversible discharges of the proton to form adsorbed hydrogen on the top side of the (110) step orientations. The possible presence of (100) steps/defects on the surface would generate a pair of peaks at different (higher) potential, ${ }^{43}$ which, as can be seen, were not present in the voltammograms shown in Figure 1. If a strongly adsorbing species was to be deposited at the top of the steps (such as the adsorption of $\mathrm{CO}$ ), the features at $\sim 0.127 \mathrm{~V}_{\mathrm{RHE}}$ would be (partially or completely) suppressed in the voltammogram. It should be noted that the pair of peaks at $\sim 0.127 \mathrm{~V}_{\mathrm{RHE}}$ would be suppressed if the bottom side of the step sites was blocked, as occurs with preferential ad-atom deposition on terraces. ${ }^{45}$ All the features below these peaks in the voltammogram (including those related to the bottom side of the steps) can be attributed to the hydrogen adsorption/desorption reactions involving Pt sites characterized as being (111) terraces. According to reaction (2), the only part of the steps characterized as being steps/defects of (110) step orientation is the top side of the steps. Hence, according to reaction (2), the hydrogen adsorption/desorption reactions at the top side of the (110) steps caused the features at $\sim 0.127 \mathrm{~V}_{\mathrm{RHE}}$, while the counterpart of the steps (the bottom side) behaved electrochemically as (111) terrace sites for hydrogen adsorption/desorption. In this process, the steps on the surface behaved as a dipole. This will be covered in detail in Section 4.2. It is worth noting that the charge density for the feature at $\sim 0.127 \mathrm{~V}_{\mathrm{RHE}}$ increased when passing from the $\mathrm{Pt}(665)$ surface to the $\operatorname{Pt}(332)$ surface (Figure 1), because the step density $\left(\rho_{(h k l)}\right)$, defined as the number of monoatomic steps per unit of length with respect to the (111) plane, follows the order $\rho_{(332)}>\rho_{(665)}$. 
The data shown in the voltammograms presented using the orange lines in Figure 1 refer to the special condition in which the top of the (110) steps of the $\operatorname{Pt}(332)$ and $\operatorname{Pt}(665)$ stepped surfaces were selectively blocked by ${ }^{13} \mathrm{C}^{16} \mathrm{O}$ (henceforth denoted ${ }^{13} \mathrm{CO}$ ). The voltammetric effects were the same, irrespective of whether the steps were blocked with ${ }^{13} \mathrm{CO}$ or ${ }^{12} \mathrm{CO}$. The experimental protocol for acquiring ${ }^{13} \mathrm{CO}$ exclusively at the top of the (110) steps consisted of partially oxidizing a ${ }^{13} \mathrm{CO}$ full coverage. For this, at a potential of $0.100 \mathrm{~V}_{\mathrm{RHE}}$, full ${ }^{13} \mathrm{CO}$ coverage was obtained by bubbling ${ }^{13} \mathrm{CO}$ gas through the solution for $5 \mathrm{~min}$, after which the solution was bubbled with Ar gas for 25 min to ensure complete removal of the nonadsorbed ${ }^{13} \mathrm{CO}$. Next, the potential was scanned from $0.100 \mathrm{~V}_{\mathrm{RHE}}$ to $0.06 \mathrm{~V}_{\mathrm{RHE}}$, at a rate of 0.05 $\mathrm{V} \mathrm{s}^{-1}$, after which the potential was switched to an upper limit value ( $E_{\mathrm{CO} \text { oxid }}$ ), such that only a small portion of the ${ }^{13} \mathrm{CO}_{\text {ads }}$ adlayer was oxidized, rather than immediate oxidation of the entire ${ }^{13} \mathrm{CO}$ adlayer. When this upper potential ( $E_{\mathrm{CO}}$ oxid $)$ was reached, the potential was stepped back to $0.100 \mathrm{~V}_{\mathrm{RHE}}$. Next, the potential was scanned into the hydrogen region, in order to probe the types of Pt sites that had been regenerated or made available for the hydrogen adsorption/desorption due to partial oxidation of the ${ }^{13} \mathrm{CO}_{\text {ads }}$ adlayer in the previous voltammetric step. On the $\operatorname{Pt}(111)$ terraced surfaces, the partial oxidation of a full CO adlayer first involved sites assigned as being the (111) terraces, while at the end, only the sites assigned as being the (110) steps remained occupied by $\mathrm{CO}_{\mathrm{ads}}$, such that the top sides of the steps were not available for the hydrogen adsorption/desorption. In the situation in which only CO species at the (110) steps were present on the Pt surface, only the features at $\sim 0.127 \mathrm{~V}_{\mathrm{RHE}}$ disappeared from the voltammogram, with the voltammograms shown in Figure 1 (orange line) corresponding to the condition where only the sites at the top of the (110) steps were occupied by ${ }^{13} \mathrm{CO}_{\mathrm{ads}}$. Successive voltammograms collected during the oxidation of a $\mathrm{CO}$ adlayer are shown in Supporting Information (Figure SI 1). All the (111) terrace sites (including the bottom sides of the steps) were available for the hydrogen adsorption/desorption. Compared to the top sides of the steps, the (111) terrace sites presented low reactivity for adsorption of carbon monoxide, as reported for studies of solid/gas interfaces. ${ }^{46,47}$ Each Pt single crystal prepared with its (110) steps selectively occupied with ${ }^{13} \mathrm{CO}_{\mathrm{ads}}$ was carefully employed for the electro-oxidation reaction of methanol and ethanol, as will be described in the next section.

In order to further demonstrate the efficiency of the procedure for acquiring adsorbed $\mathrm{CO}$ only at the top of the steps, a sample of ${ }^{12} \mathrm{CO}$ (henceforth denoted $\mathrm{CO}$ ) was used for 
decoration of the steps of a $\mathrm{Pt}(332)$ surface, using a voltammetric experimental protocol similar to that described above. After the acquisition of $\mathrm{CO}$ adsorbed on step sites, the next step was to voltammetrically oxidize these $\mathrm{CO}_{\text {ads }}$ species at once. The result is shown by the orange line in Figure 2A (together with a blank cyclic voltammogram). The maximum activity of $\mathrm{CO}$ oxidation was at $\sim 0.72 \mathrm{~V}_{\mathrm{RHE}}$ (typical of CO electro-oxidation at the top sides of the (110) steps at that potential sweep rate and solution $\mathrm{pH}^{48}$ ). The experiment for the acquisition of $\mathrm{CO}_{\mathrm{ads}}$ only on the top of the steps was repeated, this time with the $\mathrm{CO}_{\mathrm{ads}}$ being inspected by in situ FTIR spectroscopy. The results are shown in Figure 2B, including an experiment with adsorbed $\mathrm{CO}$ at full coverage. In the case of full CO coverage (presumably with all types of $\mathrm{Pt}$ active sites occupied by $\mathrm{CO}$ ), two $\mathrm{CO}_{\text {ads }}$ bands appeared in the spectra. A band at $\sim 2064 \mathrm{~cm}^{-1}$ was due to the stretching frequencies of linearly bonded CO on both (111) terraces and steps, while the band at $\sim 1830 \mathrm{~cm}^{-1}$ was attributed to bridging CO only at the (111) terraces. For the coverage condition of $\mathrm{CO}$ only on the steps, a single $\mathrm{CO}_{\text {ads }}$ band was present at $\sim 2021 \mathrm{~cm}^{-1}$, attributed to linearly bonded CO on the (110) steps (more precisely, adsorbed CO only on the top of the steps). The spectroscopic inspection of the CO only on the top of the steps was in perfect agreement with the voltammetric results (Figure 1, orange line; Figure 2A, orange line). From inspection of the spectra in Figure 2A, it can be seen that the band corresponding to linearly bonded CO only on the steps presented a redshift of about $43 \mathrm{~cm}^{-1}$, compared to the band for linearly bonded $\mathrm{CO}$ at full coverage. Previous studies showed that the intensity of the band for linearly bonded CO on (111) terraces (at higher frequencies) strongly borrowed the band intensity (at lower frequencies) of the adsorbed $\mathrm{CO}$ on the step sites. ${ }^{49} \mathrm{It}$ could be concluded that our procedure for the acquisition of $\mathrm{CO}$ exclusively on the top of the steps was successful. Furthermore, for the condition of CO only on the (110) steps, the in situ FTIR spectrum was in agreement with the $\mathrm{CO}_{\text {ads }}$ occupying the top side of the (110) steps.

\subsection{Reactivity of Stepped Pt Surfaces Toward Electro-oxidation of Methanol and Ethanol as} Monitored by Cyclic Voltammetry

The voltammetric profiles corresponding to the electro-oxidation of methanol and ethanol are shown in Figure 3. In the experimental procedure, a blank cyclic voltammogram was first recorded, followed by setting the potential of the working electrode at $0.100 \mathrm{~V}_{\mathrm{RHE}}$ and adding a sufficient volume of $0.1 \mathrm{M}$ methanol or ethanol stock solution into the electrochemical cell to give final a concentration of $5.0 \mathrm{mM}$ (methanol) or $10.0 \mathrm{mM}$ (ethanol). 
Successive cyclic voltammograms were then recorded. The two first cycles are shown in Figure 3. The measurements include a blank cyclic voltammogram for comparison. As a general feature, the voltammetric profiles for the electro-oxidation of both alcohols indicated that in the first potentiodynamic cycle, only a fraction of the (110) steps was blocked by fragments originating from the dissociation of methanol or ethanol (see the Figure 3 insert, highlighting the hydrogen region). In the first two potentiodynamic cycles, in the presence of the low concentration of alcohol in solution, the (111) terrace sites remained available for the hydrogen adsorption/desorption, indicating the low reactivity of the (111) terraces. Importantly, this did not mean a lack of catalytic activity of the (111) terrace sites, because reactivity and catalytic activity do not mean the same thing in catalysis. For methanol, in particular, the current density only started at potentials above $\sim 0.5 \mathrm{~V}_{\mathrm{RHE}}$. No hysteresis between positive and negative scan directions observed. From the voltammetric perspective, at low potentials (or $E<\sim 0.3 \mathrm{~V}_{\mathrm{RHE}}$ ), the reactivity behaviors of the $\operatorname{Pt}(332)$ surface toward adsorption/dissociation of methanol and ethanol are quite similar, with the adsorption essentially occurring at the (110) step sites. High reactivity of low coordinated atoms for alcohols dissociation has been expected from Density Functional Theory (DFT) calculations. ${ }^{50,51}$

The voltammetric profiles for the electro-oxidation of methanol and ethanol on the $\mathrm{Pt}(665)$ single crystal surface (see Supporting Information) were qualitatively similar to those for $\mathrm{Pt}(332)$. In situ FTIR spectroscopy experiments were performed employing stepped $\mathrm{Pt}$ surfaces where the steps were selectively blocked by ${ }^{13} \mathrm{CO}$.

\subsection{Control of the Band of ${ }^{13} \mathrm{CO}_{2}$ from the Electro-oxidation of a Common Methanol Sample}

Unlike the electro-oxidation of ethanol, the electro-oxidation of methanol on a $\mathrm{Pt}$ catalyst at high potentials (above $\sim 0.7 \mathrm{~V}_{\mathrm{RHE}}$ ) results in massive production of carbon dioxide. At high concentrations of methanol, two carbon dioxide bands appear in the FTIR spectra. Since one of the goals in this work was to detect the small band of the ${ }^{13} \mathrm{CO}_{2}$ derived from electro-oxidation of the ${ }^{13} \mathrm{CO}_{\text {ads }}$ species previously deposited on the (110) steps of the $\mathrm{Pt}$ surface, it was necessary to eliminate the contribution of the ${ }^{13} \mathrm{CO}_{2}$ band that appears naturally in the spectrum for the electro-oxidation of common methanol. Common methanol refers to a methanol sample that contains the natural abundance of the stable carbon isotopes $\left({ }^{12} \mathrm{C}\right.$ and $\left.{ }^{13} \mathrm{C}\right)$. 
After preparing the $\operatorname{Pt}(332)$ electrode in the electrochemical cell, the potential was set at $0.100 \mathrm{~V}$ and a sufficient volume of $0.1 \mathrm{M}$ methanol stock solution was added to the cell to give a final methanol concentration of $50.0 \mathrm{mM}$. After homogenization of the solution, the surface of the Pt crystal was positioned against the optical window and spectra were recorded at potentials ranging from 0.05 to $0.80 \mathrm{~V}$, in intervals of $25 \mathrm{mV}$. Selected spectra from this experiment are shown in Figure 4A. The electro-oxidation of methanol was also performed at lower concentrations $(10.0,5.0,1.0$, and $0.5 \mathrm{mM})$. The result for a $5.0 \mathrm{mM}$ methanol solution is shown in Figure 4B.

For $50.0 \mathrm{mM}$ methanol, the spectra showed two bands corresponding to the asymmetric stretching mode of carbon dioxide. A dominant band at $2343 \mathrm{~cm}^{-1}$, starting at $\sim 0.4 \mathrm{~V}_{\mathrm{RHE}}$, was attributed to ${ }^{12} \mathrm{CO}_{2}$, while another small band at $2277 \mathrm{~cm}^{-1}$, starting at about $0.6 \mathrm{~V}_{\mathrm{RHE}}$, was attributed to ${ }^{13} \mathrm{CO}_{2}$. The band at $2277 \mathrm{~cm}^{-1}\left({ }^{13} \mathrm{CO}_{2}\right)$ became more intense when the potential was set above $0.7 \mathrm{~V}_{\mathrm{RHE}}$, associated with an increasing rate of methanol electro-oxidation. At concentrations of around $5 \mathrm{mM}$ and below, the ${ }^{13} \mathrm{CO}_{2}$ band no longer appeared in the spectra, even at higher potentials such as $0.7 \mathrm{~V}_{\mathrm{RHE}}$. The bipolar band $\left(2021 \mathrm{~cm}^{-1}-2043 \mathrm{~cm}^{-1}\right)$ indicated the presence of adsorbed $\mathrm{CO}$ on the electrode surface at the potential of the reference spectrum $\left(0.100 \mathrm{~V}_{\mathrm{RHE}}\right)$. In the series of spectra shown in Figure 4 , all the bands at around 1600 $\mathrm{cm}^{-1}$ were affected by the broad and dominant band of the uncompensated water bending mode at $1650 \mathrm{~cm}^{-1}$; these bands were not considered, since they had no analytical purpose in this work. The series of spectra showed no bands due to the presence of formic acid, at $\sim 1712$ $\mathrm{cm}^{-1}$ (due to carboxylic acid $\mathrm{C}=\mathrm{O}$ stretching vibration). ${ }^{52}$ This suggested that for the thin layer configuration, carbon dioxide was the single soluble final product from the electro-oxidation of methanol. It was not possible to know whether any small amount of formic acid (and even formaldehyde) produced was rapidly oxidized to carbon dioxide.

For a series of experiments using $50.0 \mathrm{mM}$ methanol, the magnitudes of the bands $\left(A_{i}\right)$ for both ${ }^{13} \mathrm{CO}_{2}$ and ${ }^{12} \mathrm{CO}_{2}$ were integrated for spectra acquired at 0.7 and $0.8 \mathrm{~V}_{\mathrm{RHE}}$. A ratio of $\sim 1 / 102$ (within experimental error) was obtained for the $A\left({ }^{13} \mathrm{CO}_{2}\right) / A\left({ }^{12} \mathrm{CO}_{2}\right)$ bands, in agreement with the natural ${ }^{13} \mathrm{C}$ abundance of $\sim 1.06 \% .{ }^{53}$ For methanol concentrations of around $5 \mathrm{mM}$ (see Figure 4B) and below, the contribution of the ${ }^{13} \mathrm{CO}_{2}$ band did not exceed the level of the spectral noise, which was the desired experimental condition.

It should be noted that the band at $2277 \mathrm{~cm}^{-1}$ appears clearly in spectra for the electrooxidation of common glycerol $(50 \mathrm{mM})^{54}$ and common formic acid (1 M) ${ }^{55}$ on Pt electrodes, 
at potentials at which massive production of carbon dioxide occurs. For the electro-oxidation of ethanol on a Pt electrode, the carbon dioxide production is so low, even at $75 \mathrm{mM}$ ethanol, that a single carbon dioxide band (corresponding to ${ }^{12} \mathrm{CO}_{2}$ ) appears in the spectra. ${ }^{54}$

\subsection{Electro-oxidation of Alcohols on Stepped Pt Single Crystal Surfaces with the (110) Steps Marked with ${ }^{13} \mathrm{CO}_{\text {ads }}$ as Monitored by in situ FTIR Spectroscopy}

\subsubsection{Electro-oxidation of Methanol on Pt(332) steps ${ }^{13} \mathrm{CO}$ and Pt $(665)_{\text {steps }}{ }^{13} \mathrm{CO}$ Surfaces}

As discussed in Section 3.1, the top side of the (110) steps of the surfaces of the $\operatorname{Pt}(332)$ and $\operatorname{Pt}(665)$ single crystals was selectively occupied with ${ }^{13} \mathrm{CO}_{\text {ads }}$. Here, these "chemically modified" catalyst surfaces are denoted as $\mathrm{Pt}(332)_{\text {steps }} /{ }^{13} \mathrm{CO}$ and $\mathrm{Pt}(665)_{\text {steps }} /{ }^{13} \mathrm{CO}$ for $\mathrm{Pt}(332)$ and $\mathrm{Pt}(665)$, respectively. The experiments corresponding to these two chemically marked electrodes are shown in Figure 1 (orange line). The acquisition of the in situ FTIR spectra was according to the following experimental protocols. After acquisition of ${ }^{13} \mathrm{CO}_{\text {ads }}$ on the (110) steps (Figure 1, orange line), the electrode was kept at $0.100 \mathrm{~V}_{\mathrm{RHE}}$ and a sufficient volume of $0.1 \mathrm{M}$ methanol stock solution was added to the spectro-electrochemical cell to give a final methanol concentration of $1.0 \mathrm{mM}$. The solution was briefly homogenized, after which the crystal was pressed against the optical window. It is important to note that the electrode was not depolarized at any stage of the experiments. A series of spectra was then recorded at different potentials. The results for the electro-oxidation of $1.0 \mathrm{mM}$ methanol on the $\mathrm{Pt}(332)_{\text {steps }} /{ }^{13} \mathrm{CO}$ electrode are shown in Figure 5. Then, the series of spectra shown in Figure 5 were recorded employing the $\operatorname{Pt}(332)$ surface with the top side of the (110) steps decorated with ${ }^{13} \mathrm{CO}_{\text {ads }}$ shown in Figure 1 in the orange line. Since the electro-oxidation of methanol at very low concentration, under the thin layer configuration, results in carbon dioxide as the only reaction product (see Figure 4), only the wavenumber regions containing signals for the carbon dioxide $\left({ }^{13} \mathrm{CO}_{2}\right.$ and $\left.{ }^{12} \mathrm{CO}_{2}\right)$ and $\mathrm{CO}_{\text {ads }}$ bands will be shown (full spectra in Supporting Information). For $\mathrm{Pt}(332)_{\text {steps }} /{ }^{13} \mathrm{CO}+1.0 \mathrm{mM}$ methanol (Figure 5), the spectra exhibited two carbon dioxide bands. A band centered at $2343 \mathrm{~cm}^{-1}$ appeared at a potential of $0.45 \mathrm{~V}_{\mathrm{RHE}}$, while another band centered at $2277 \mathrm{~cm}^{-1}$ appeared at $\sim 0.62 \mathrm{~V}_{\text {RHE }}$. The band at $2343 \mathrm{~cm}^{-1}$ was due to carbon dioxide produced from electro-oxidation of the methanol. The band at $2277 \mathrm{~cm}^{-1}$ was due to electro-oxidation of the ${ }^{13} \mathrm{CO}_{\text {ads }}$ previously deposited at the top of the steps of the $\mathrm{Pt}(332)$ surface. As expected, the band at $2277 \mathrm{~cm}^{-1}$ was small, compared to the band at 2343 $\mathrm{cm}^{-1}$. At potentials above $0.77 \mathrm{~V}_{\mathrm{RHE}}$, the band at $2277 \mathrm{~cm}^{-1}$ completely disappeared, probably 
due to the following reasons: (i) all the ${ }^{13} \mathrm{CO}_{\text {ads }}$ species had already been oxidized at $0.77 \mathrm{~V}_{\mathrm{RHE}}$; (ii) there was no external source of ${ }^{13} \mathrm{CO}_{\text {ads }}$ species, that is, there was no ${ }^{13} \mathrm{CO}_{\text {ads }}$ other than that previously adsorbed on the electrode surface; (iii) the molecules of ${ }^{13} \mathrm{CO}_{2}$ diffused from the thin layer. Once the top of the steps were released during the electro-oxidation of the previously attached ${ }^{13} \mathrm{CO}_{\mathrm{ads}}$, these $\mathrm{Pt}$ sites probably became available for the dissociation/oxidation of methanol molecules, with $\mathrm{CO}_{\text {ads }}$ species being among the fragments. However, at potentials above $\sim 0.7 \mathrm{~V}_{\mathrm{RHE}}$, the band at $2343 \mathrm{~cm}^{-1}$ decreased slightly, probably due to depletion of methanol (initially $1.0 \mathrm{mM}$ ) in the thin layer.

Considering the band for adsorbed $\mathrm{CO}$, there was no evidence of a signal for the ${ }^{13} \mathrm{CO}_{\mathrm{ads}}$ species. This was because coupling between dipoles caused the transfer of intensity to the band at higher frequency (such as for linearly bonded CO on the terraces), at the expense of the intensity of the band at lower frequency (such as for linearly bonded CO at the steps). ${ }^{49,56}$ Hence, in the presence of both ${ }^{12} \mathrm{CO}_{\mathrm{ads}}$ and ${ }^{13} \mathrm{CO}_{\mathrm{ads}}$, the phenomenon of band intensity transfer may result in the band for ${ }^{13} \mathrm{CO}_{\text {ads }}$ being undetected or invisible in the spectra. Previous work has shown that for ${ }^{13} \mathrm{CO} /{ }^{12} \mathrm{CO}$ mixtures, the ${ }^{13} \mathrm{CO}_{\text {ads }}$ band becomes visible in the spectrum when the amount of ${ }^{13} \mathrm{CO}$ present in the mixture is around $80 \% .{ }^{57}$ In the present case, the amount of ${ }^{13} \mathrm{CO}_{\text {ads }}$ was very low (and restricted only to the (110) steps), which probably explained why no bands for ${ }^{13} \mathrm{CO}_{\text {ads }}$ were observed in the spectra.

Other considerations should be highlighted regarding the experimental procedures for recording of the experiment shown in Figure 5. The electrode potential remained at $0.10 \mathrm{~V}$ for a longer time in the experiment shown in Figure 5, compared to the experiment shown in Figure 3. In the case of the purely electrochemical experiment (Figure 3), methanol was added to the electrochemical cell and the potential then remained at $0.100 \mathrm{~V}_{\mathrm{RHE}}$ for only a few seconds, followed by recording the voltammetric scans. On the other hand, in the spectroelectrochemical experiments, after the addition of the alcohol to the electro-chemical cell and pressing the electrode against the optical window, sufficient time was always allowed for stabilization of the thin layer, and only after that were the spectra recorded. This procedure could take up to 2 minutes or more. Furthermore, the time required for acquisition and storage of one spectrum was around 2 minutes. Consequently, in the case of the spectroelectrochemical experiments, due to the long waiting time at $0.100 \mathrm{~V}_{\mathrm{RHE}}$, there was probably the accumulation of alcohol fragments on the electrode surface. This was why the (bipolar) band of $\mathrm{CO}_{\text {ads }}$ at $2043 \mathrm{~cm}^{-1}$, likely due to ${ }^{12} \mathrm{CO}_{\text {ads }}$ formation on the (111) terraces, appeared in 
the spectra shown in Figure 4. Consequently, the intense band for ${ }^{12} \mathrm{CO}_{\mathrm{ads}}$ on the (111) terraces masked the band for the ${ }^{13} \mathrm{CO}_{\text {ads }}$ species on the top of the steps. Different to the spectroelectrochemical experiment, the voltammetry results for the electro-oxidation of methanol (Figure 3) suggested that there was no formation of $\mathrm{CO}_{\mathrm{ads}}$ on the terraces. This difference is intrinsic to in situ FTIR spectroscopy experiments.

Data for the electro-oxidation of $1.0 \mathrm{mM}$ methanol on a $\mathrm{Pt}(665)_{\text {steps }}{ }^{13} \mathrm{CO}$ electrode are shown in Figure 6. The spectra were recorded employing the $\operatorname{Pt}(665)$ with the top of the steps decorated with ${ }^{13} \mathrm{CO}_{\text {ads }}$ (Figure 1, orange line). For simplicity, only the regions of the spectra containing the carbon dioxide bands are shown. The same features described for the $\mathrm{Pt}(332)_{\text {steps }} /{ }^{13} \mathrm{CO}$ electrode were valid for the $\mathrm{Pt}(665)_{\text {steps }} /{ }^{13} \mathrm{CO}$ electrode. As expected ${ }^{26}$, step sites are highly active for splitting of $\mathrm{C}-\mathrm{H}$ bond and forming $\mathrm{CO}_{\mathrm{ads}}$. Another general observation was that for the two stepped Pt surfaces, a higher potential was required for the formation of carbon dioxide from the electro-oxidation of carbon monoxide at the top side of the steps, compared to the formation of carbon dioxide from the $\mathrm{CO}_{\mathrm{ads}}$ on the rest of the $\mathrm{Pt}$ sites, which were assigned as being the (111) terrace sites. In this sense, the experiment carried out with $\mathrm{Pt}(332)_{\text {steps }} /{ }^{13} \mathrm{CO}+1.0 \mathrm{mM}$ methanol and $\operatorname{Pt}(665)_{\text {steps }} /{ }^{13} \mathrm{CO}+1.0 \mathrm{mM}$ methanol revealed the existence of two routes of carbon dioxide formation, whose activation involved the top side of the steps and the (111) terraces on the same Pt surface. This experiment also enabled the chemistry at different points on the surface to be molecularly monitored.

\subsubsection{Electro-oxidation of Ethanol on Pt(332) steps $^{13} \mathrm{CO}$}

Similar experiments were performed employing the $\mathrm{Pt}(332)_{\text {steps }}{ }^{13} \mathrm{CO}$ electrode in the presence of $10.0 \mathrm{mM}$ ethanol. In the case of ethanol, the study to determine the best ethanol concentration (which was performed for methanol) was not necessary, because the electrooxidation of ethanol on Pt electrodes produces little carbon dioxide. The experimental protocol employed for the electro-oxidation of ethanol was similar to that used for methanol. The results are shown in Figure 7. In the case of the electro-oxidation of ethanol, other reaction products are formed, besides carbon dioxide. Hence, the spectra shown include the spectral region for acetic acid and acetaldehyde. A band at $2343 \mathrm{~cm}^{-1}$, starting at $\sim 0.47 \mathrm{~V}_{\mathrm{RHE}}$, was due to the ${ }^{12} \mathrm{CO}_{2}$ originated from the electro-oxidation of ethanol on the (111) terraces. A band at $2277 \mathrm{~cm}^{-1}$, appearing at a potential of $\sim 0.62 \mathrm{~V}_{\mathrm{RHE}}$, was due to the electro-oxidation of ${ }^{13} \mathrm{CO}_{\text {ads }}$ previously deposited at the top side of the steps of the $\mathrm{Pt}(332)$ surface. The band at 
$\sim 2051 \mathrm{~cm}^{-1}$ refers to the stretching frequencies of adsorbed CO, dominantly on the (111) terraces. Because of the band intensity transfer (explained above) the band of ${ }^{13} \mathrm{CO}_{\text {ads }}$ on step sites is not observed. ${ }^{49,56,57}$ Generally, the in situ FTIR data confirm that steps on surfaces are high active toward splitting of $\mathrm{C}-\mathrm{C}$ and $\mathrm{C}-\mathrm{H}$ bonds. ${ }^{50}$ At lower wavenumber, the dominant uncompensated water bending mode band was present at $1650 \mathrm{~cm}^{-1}$. A band at $1413 \mathrm{~cm}^{-1}$, which shifted toward higher wavenumber as the potential was increased, could be attributed to symmetric OCO stretching of the $-\mathrm{COO}^{-}$group (adsorbed acetate). This band appeared in the spectra at a potential of $\sim 0.62 \mathrm{~V}_{\mathrm{RHE}}$, the same potential as for initiation of the pathway of electro-oxidation of adsorbed CO present on the top side of the steps. A band at $1282 \mathrm{~cm}^{-1}$ was due to the combined $\mathrm{C}-\mathrm{O}$ stretching and $\mathrm{OH}$ deformation of the $\mathrm{COOH}$ group of acetic acid. ${ }^{41}$ It should be noted that the intense water band at around $1650 \mathrm{~cm}^{-1}$ (corresponding to the water bending mode) obscured the possible acetaldehyde band that should appear at 1717 $\mathrm{cm}^{-1},{ }^{41}$ corresponding to the stretching of $\mathrm{C}=\mathrm{O}$ of acetaldehyde or acetic acid $(\mathrm{CHO}$ or $\mathrm{COOH}$ groups, respectively).

\section{Discussion}

This paper reports a direct spectroscopic disentangling of the set of specific electrocatalytic active sites involved in different reaction pathways of carbon dioxide formation during the electro-oxidation of methanol and ethanol on Pt electrodes in an acid solution. The set of experiments allows a more complete characterization of the complex interplay involving steps/defects on $\mathrm{Pt}$ surfaces during the electrocatalytic oxidation of alcohols.

\subsection{Identity of the Active Sites Involved in the Formation of $\mathrm{CO}_{2}$ and the Formation of Acetic Acid}

The mechanisms of the electrochemical oxidation of methanol and ethanol involve a series of proton-coupled electron transfer steps. Based on thermodynamic considerations, ${ }^{58}$ the standard potentials (at $\mathrm{pH}=0$ ) characteristic of the electro-oxidation of each of these alcohols to $\mathrm{CO}_{2}$ are as follows:

$$
\begin{aligned}
& \mathrm{CH}_{3} \mathrm{OH}_{(\mathrm{l})}+\mathrm{H}_{2} \mathrm{O}_{(\mathrm{l})} \rightleftarrows \mathrm{CO}_{2(\mathrm{~g})}+6 \mathrm{H}^{+}+6 e^{-} ; E^{0} \simeq 0.016 \mathrm{~V}_{\mathrm{SHE}} \\
& \mathrm{H}_{3} \mathrm{C}-\mathrm{CH}_{2} \mathrm{OH}_{(\mathrm{l})}+3 \mathrm{H}_{2} \mathrm{O}_{(\mathrm{l})} \rightleftarrows 2 \mathrm{CO}_{2(\mathrm{~g})}+12 \mathrm{H}^{+}+12 e^{-} ; E^{0} \simeq 0.085 \mathrm{~V}_{\mathrm{SHE}}
\end{aligned}
$$


Taking $\mathrm{CO}_{2}$ as the reaction product from electro-oxidation of the alcohol, the most active sites are those able to activate the reaction pathway of $\mathrm{CO}_{2}$ formation at lower overpotentials, that is, the active sites which require lower energy input during the electrooxidation of methanol or ethanol toward carbon dioxide, under specified conditions. According to the in situ FTIR spectroscopic data (shown in Figures 5, 6, and 7), the onset potential at which the band for ${ }^{13} \mathrm{CO}_{2}$ appeared in the spectra was $\sim 0.62 \mathrm{~V}_{\mathrm{RHE}}$. The carbon monoxide whose electro-oxidation originated the ${ }^{13} \mathrm{CO}_{2}$ was the ${ }^{13} \mathrm{CO}_{\text {ads }}$ species selectively adsorbed on the top side of the (110) steps. Therefore, for the condition under which the ${ }^{13} \mathrm{CO}_{\text {ads }}$ exclusively occupied the top of the (110) steps, the only set of sites available for interaction with the alcohol molecules and their oxidation were the sites assigned as being the (111) terraces. In the experiments shown in Figures 5, 6, and 7, the band for $\mathrm{CO}_{2}$ formed from the electro-oxidation of the alcohols appeared at a potential of $\sim 0.45 \mathrm{~V}_{\mathrm{RHE}}$, which was lower than the potential at which the oxidation of ${ }^{13} \mathrm{CO}_{\mathrm{ads}}$ on the top of the (110) steps occurred. It could therefore be concluded that the set of most active sites involved in the formation of $\mathrm{CO}_{2}$ from the alcohols undoubtedly resided at the (111) terraces of the stepped Pt surfaces. However, in order to find the lowest potential for activation of the pathway for formation of $\mathrm{CO}_{2}$ on the (111) terraces, it was necessary to consider that the potential for initiation of $\mathrm{CO}_{2}$ formation depended on the concentration of the alcohol (Figure 4). Furthermore, it is reasonable to assume that the ${ }^{13} \mathrm{CO}_{\text {ads }}$ species (previously adsorbed on specific sites) behaves chemically in a similar way to the ${ }^{12} \mathrm{CO}_{\mathrm{ads}}$ originated from the dissociation of the alcohols. Thus, both ${ }^{12} \mathrm{CO}_{\text {ads }}$ and ${ }^{13} \mathrm{CO}_{\text {ads }}$ behave electrochemically as if they were species (or reaction intermediates) derived from dissociation of the alcohol. It is then reasonable to suppose that in the absence of ${ }^{13} \mathrm{CO}_{\text {ads }}$ species marking the top of the (110) step sites, the initiation of the electro-oxidation reactions of the alcohols also involves the same set of most active sites that manifested in the presence of ${ }^{13} \mathrm{CO}_{\mathrm{ads}}$ marking step sites. Considering all this, the electro-oxidation reaction of methanol towards $\mathrm{CO}_{2}$ started at about $\sim 0.40 \mathrm{~V}_{\mathrm{RHE}}$ for $50.0 \mathrm{mM}$ methanol (Figure $4 \mathrm{~A}$ ). Therefore, based on the spectroscopic experiments, it can be concluded that the most active sites, which require lower overpotentials (or lower energy input) for activation of the pathway for carbon dioxide formation, reside at the (111) terraces of the stepped surfaces, probably closer to the bottom side of the (110) steps, which are the (111) terrace sites. On the other hand, the sites requiring higher over-potential (or higher energy input) for the initiation of $\mathrm{CO}_{2}$ formation were at the top 
side of the steps. Under the condition where all the steps were chemically marked with ${ }^{13} \mathrm{CO}_{\mathrm{ads}}$ species, the difference of potential for activation of the pathways for $\mathrm{CO}_{2}$ formation on the (111) terraces (the location of the most active sites) and on the top side of the steps (which behaved as the least active sites) was of the order of $\Delta E \simeq 0.22 \mathrm{~V}(\equiv 0.62 \mathrm{~V}-0.40 \mathrm{~V})$. Hence, the most active sites and least active sites were energetically separated by about $\sim 0.22 \mathrm{~V}$, which is a substantial difference. The experimental strategy of site-specific marking using isotope-labeled species was successful and allowed direct disentanglement of the catalytic activities related to the terraces and the steps on the same catalyst surface. Although the tops of the step sites were highly active for the dissociation of alcohols (see Figures 3-7), these sites were not able to act in the $\mathrm{CO}$ oxidation step at low potentials, including the incorporation of any type of oxygen-containing species originating from the interfacial water molecules: $\mathrm{CO}_{\text {ads }}+\left(\mathrm{H}_{2} \mathrm{O}\right)_{\text {species }} \rightarrow \mathrm{CO}_{2}+2 \mathrm{H}^{+}+2 e^{-}+{ }^{*}$ free Pt sites Since there was a large difference $(\Delta E \simeq 0.22$ $\mathrm{V})$ between the potential for activation of the pathway of $\mathrm{CO}_{2}$ formation on the (111) terraces and the potential for electro-oxidation of $\mathrm{CO}_{\mathrm{ads}}$ on the top side of the steps, the results (shown in Figures 4-7) suggested that at potentials less than $\sim 0.62 \mathrm{~V}_{\mathrm{RHE}}$, all the sites characterized as being at the top side of the steps remained entirely poisoned with $\mathrm{CO}_{\mathrm{ads}}$ species. Therefore, $\mathrm{CO}_{\mathrm{ads}}$ at the top side of the steps behaved chemically as a catalytic poison, whereas $\mathrm{CO}_{\mathrm{ads}}$ on the (111) terrace sites along the stepped surface behaved chemically more like an active reaction intermediate. The controversial question about the role played by the $\mathrm{CO}_{\text {ads }}$ species in catalysis of the electro-oxidation of small organic molecules is now better understood. This question was addressed by Weaver et al. ${ }^{59}$ in the 1980 s, according to whom the $\mathrm{CO}_{\text {ads }}$ species obtained from the dissociation of alcohols acts as a catalytic poison. In contrast, Iwasita and Camara ${ }^{60}$ considered that the $\mathrm{CO}_{\mathrm{ads}}$ species behaves chemically purely as a reaction intermediate. Neither possibility is entirely accurate. As we have shown above, the action of $\mathrm{CO}_{\mathrm{ads}}$ as a poison or as a reaction intermediate depends on the type of site at which the $\mathrm{CO}_{\mathrm{ads}}$ resides, as well as on the potential. Our results provides further information about the chemistry intrinsic to the top side of the step sites, compared to the chemical properties of the (111) terraces on the same surface.

The complexity of the catalytic behavior of the step sites on the $\operatorname{Pt}(111)$ terraced surfaces is further increased considering the route for the electro-oxidation of ethanol toward acetic acid. As shown in Figure 7, activation of the pathway for acetic acid formation occurred at $\sim 0.62 \mathrm{~V}_{\mathrm{RHE}}$, which was the same as the potential for oxidation of $\mathrm{CO}$ on the top of the steps. 
This evidenced that the pathway for acetic acid formation was not activated on the (111) terraces of the stepped Pt surface, at least at potentials below $\sim 0.62 \mathrm{~V}_{\mathrm{RHE}}$. This was in direct contrast to the catalytic behavior of the $\mathrm{Pt}(111)$ basal plane, which is active in the electrooxidation of ethanol toward acetic acid, whose formation on $\operatorname{Pt}(111)$ basal plane occurs at a potential of $\sim 0.4 \mathrm{~V}_{\text {RHE. }}{ }^{18}$ Therefore, since acetic acid is not formed until the top side of the step sites are released due to the electro-oxidation of $\mathrm{CO}_{\mathrm{ads}}$, the reaction pathway for acetic acid formation is kinetically hindered by the presence of the $\mathrm{CO}_{\text {ads }}$ on the top side of the steps, in accordance with previous results..$^{38}$ Our results shed light to the understand information of the reasons why acetic acid formation on stepped Pt surfaces always takes place at potentials greater than the onset potential of $\mathrm{CO}_{2}$ formation (as we can see in in situ FTIR spectra of ethanol electro-oxidation on stepped Pt surfaces in acid media elsewhere ${ }^{50,61}$ ). Moreover, our results explain why the activation pathway of acetic acid formation is favored in defected surfaces at potentials above $\sim 0.7 \mathrm{~V}_{\mathrm{RHE}}$, as reported by Colmati et al. ${ }^{19}$ for a series of stepped Pt surfaces. Then, in contrast to the formation of $\mathrm{CO}_{2}$ (which requires the incorporation of any sort of oxygen-containing species into $\mathrm{CO}$ ), in the case of acetic acid formation, the incorporation of oxygen-containing species into the ethanol intermediate preferentially occurs on the top side of the steps. Therefore, since acetic acid is formed on the "infinitely wide" (111) terraces of the platinum at low potentials (about $0.4 \mathrm{~V}_{\mathrm{RHE}}$ ), ${ }^{18}$ but is not formed on terraces of the stepped surfaces at similar potentials, this suggests that the chemical or catalytic properties of the (111) terraces of the quasi-perfect $\mathrm{Pt}(111)$ surfaces differ from the (111) terraces of the stepped surfaces. The structural difference between these two surfaces is related to the presence of steps/defects on the latter type of surface.

\subsection{Interplay of Steps/Defects in the "Creation" of the Most Active Sites on the (111) Terraces of the Pt Surfaces}

On the basis of the discussion in Section 4.1, it is clear that the most active sites at which the carbon dioxide is preferentially formed reside at the (111) terraces of the stepped surfaces. However, it is true that the quasi-perfect $\operatorname{Pt}(111)$ or "infinitely wide" (111) terraces have low activity in activation of the pathway for carbon dioxide formation from the electro-oxidation of alcohols, ${ }^{18,23}$ with almost no carbon dioxide formed from the electro-oxidation of ethanol on a quasi-perfect $\operatorname{Pt}(111)$ surface. ${ }^{18}$ Therefore, the preferential activation of the pathway for carbon dioxide formation on the (111) terraces of stepped surfaces suggests that the presence 
of the steps changes the catalytic properties of the (111) terraces. Another example concerns the "inhibition" of the reaction pathway for acetic acid formation from the electro-oxidation of ethanol on (111) terraces of stepped surfaces (highlighted above), while the (111) terraces of the $\mathrm{Pt}(111)$ basal plane are very active toward acetic acid formation. ${ }^{18}$ These two examples suggest that the catalytic properties of the (111) terraces on stepped surfaces arise due to the presence of the steps. Steps on surfaces may be understood as a dipole on the surface (as depicted in Figure 1), where there is a charge redistribution involving a lack of charge $(+)$ at the top side of the step and charge accumulation (-) in the counter-part (or bottom side) of the step. For a metallic surface, this is known as the Smoluchowski effect. ${ }^{62}$ From the chemical (or catalytic) perspective, the interplay of the steps/defects on the surface gives rise to a new reaction pathway favoring $\mathrm{CO}_{2}$ formation on the (111) terraces during the electro-oxidation of alcohols. At the same time, the pathway of another reaction (acetic acid formation) may be inhibited at these same (111)-type terrace sites, due to the action of the steps. Therefore, the steps/defects on the surfaces have multi-functionality and these attributes can change the chemical properties of the neighboring (111) terrace sites. Hence, the steps on the surface alter the chemistry on the (111) terraces, making them active for a reaction pathway that is completely inactive on the "infinitely wide" (111) planes, or inhibiting a reaction pathway that is favorable on the "infinitely wide" (111) planes.

The sites on which the sources of oxygen-containing species (from water) were formed could be inferred from the spectra for the electro-oxidation of methanol and ethanol on $\mathrm{Pt}$ surfaces where the top sides of the steps were chemically marked with ${ }^{13} \mathrm{CO}_{\mathrm{ads}}$, together with the knowledge that the $\mathrm{CO}_{2}$ formation pathway was activated on the (111) terraces before the top of the (110) steps were released. Given that the top of the (110) steps was blocked by ${ }^{13} \mathrm{CO}_{\text {ads }}$ and that the reaction pathway for $\mathrm{CO}_{2}$ formation was preferentially activated on the (111) terraces (Figures 5,6 and 7), it is likely that the oxygenated species from water were also formed on the terraces (and not on the steps). Hence, at potentials below $\sim 0.62 \mathrm{~V}_{\mathrm{RHE}}$, the (111) terraces participated in activation of the pathway for $\mathrm{CO}_{2}$ formation when the tops of the step sites were entirely blocked (poisoned) with ${ }^{13} \mathrm{CO}_{\text {ads }}$ (see Figures 5, 6, and 7). Consequently, all the electrochemical events that resulted in the formation of $\mathrm{CO}_{2}$ occurred on the domains of the (111) terraces of the stepped Pt surfaces. This suggests that for activation of the pathway for $\mathrm{CO}_{2}$ formation on the (111) terraces, at low potentials, the role played by steps/defects on the surface was physical in nature (since no elementary step of the catalyzed 
reaction occurred at these sites), rather than chemical, as previously thought. This enables information to be obtained about the role of the structure in the catalytic phenomena. From the surface structure point of view, the nature of an active site includes a local part of the set of atoms on the surface of the catalytic substrate. However, it must also be taken into account the influence coming from the surrounding environment, where it is probable that there was no direct contribution to the elementary steps of the catalyzed reaction, although this surrounding environment is fundamental for configuring the "ideal" condition for the catalytic phenomenon. Considering that the entire (111) terraces of stepped Pt surfaces are more catalytically active for $\mathrm{CO}_{2}$ formation, compared to the top side of the steps, it is reasonable that the concept of most active sites on $\mathrm{Pt}(111)$ terraced surfaces must include the influence of the steps toward the terraces. At least in the case of stepped Pt surfaces and the two reactions considered in this study, the concept of the most active site does not seem to be something confined locally to the place where the reaction (elementary) steps are developed.

The present article does not discuss the importance of the extrinsic surface part (the electrolyte ${ }^{63,64}$ ) in the configuration of the active sites. In this sense, we make the concept of active site more general in 2-dimension. It can be concluded that the steps act in modifying their neighboring environments, which results in favoring activation of the pathway for $\mathrm{CO}_{2}$ formation at the (111) terraces (while other reaction pathways are inhibited in this places). At the limit of the terraces of the stepped surfaces, the most active sites for $\mathrm{CO}_{2}$ formation reside at the bottom side of the (110) steps or the locally concave structure (see Figure 1), which for the reaction of hydrogen adsorption/desorption $\left(\mathrm{H}_{\mathrm{ads}} \rightleftarrows \mathrm{H}^{+}+e^{-}+{ }^{*}\right.$ available Pt sites $)$ behave as being the (111) terrace sites. In this regard, it should be highlighted that optimizing the population of the most active sites on the surfaces requires the employment of Pt surfaces with shorter terraces. Account must be taken of the three-dimensional electrochemical environment in which the site resides, considering the structural characteristics of the interface, nature of the electrolyte and mass transport.

\subsection{The Chemical Reactions Concerning $\mathrm{CO}_{2}$ Formation}

In this paper, we analyze the pathway of $\mathrm{CO}_{2}$ formation during the electro-oxidation of methanol (and ethanol) involving $\mathrm{CO}_{\mathrm{ads}}$. The specificity of the experiments precluded a more accurate elucidation of the $\mathrm{CO}_{\text {ads }}$ pathway. Based on the experimental results shown in Figures 5, 6, and 7, from the surface structure viewpoint, there were two channels of $\mathrm{CO}_{2}$ 


\section{Main Conclusions}

This paper reports specific experiments designed to decipher the nature of the active sites involved in the electro-oxidation of methanol and ethanol at Pt electrodes, from which the following main conclusions can be drawn:

i. The electro-oxidation reactions of methanol and ethanol present the same types of surface structures behaving as the most active sites for activation of the pathway for $\mathrm{CO}_{2}$ formation. On $\mathrm{Pt}(111)$ terraced surfaces, the most active sites reside on the (111) terraces, while the least active sites reside on the top of the steps. The reaction pathways related to the most active sites and least active sites are separated by about $\sim 0.22 \mathrm{~V}$.

ii. In the electro-oxidation of methanol and ethanol toward $\mathrm{CO}_{2}$ by means of the $\mathrm{CO}_{\mathrm{ads}}$ pathway, the lowest catalytic activity at the top of the steps implied that at that location, the $\mathrm{CO}_{\text {ads }}$ acted mainly as a catalytic poison, while $\mathrm{CO}_{\text {ads }}$ on the (111) terraces behaved as an active reaction intermediate. 
iii. The existence of the most active sites residing on the (111) terraces is linked to the influence of the physical nature of the steps toward the terrace domains. In comparison to the "infinitely wide" (111) terraces, the existence of the steps/defects on the surface changes the chemical properties of the (111) terraces of the stepped surfaces, favoring activation of the reaction pathway for $\mathrm{CO}_{2}$ formation. Additionally, in the case of ethanol, the presence of steps on the surface inhibits the pathway of acetic acid formation on the (111) terraces. The pathway of acetic acid formation is only activated when the top of the steps starts to be released due to $\mathrm{CO}_{\text {ads }}$ electro-oxidation at these sites. The role played by steps/defects in the creation of most active sites for the formation of $\mathrm{CO}_{2}$ on terraces was physical in nature, rather than chemical, since no elementary step of the catalyzed reaction occurred at them. Therefore, the concept of active site was made more general, involving two dimensions.

\author{
Associated Content \\ Supporting Information \\ Additional experimental results, including the cyclic voltammetry and in situ FTIR data \\ (PDF).
}

\title{
Acknowledgments
}

M.J.S.F. is grateful to PNPD/CAPES (Brazil). A.A.T acknowledges CAPES (PROCAD-2013) and CNPq (309066/2013-1). J.M.F. thanks the MINECO (Spain) project CTQ2016-762213-P. 


\section{References}

(1) Corma, A. Heterogeneous Catalysis: Understanding for Designing, and Designing for Applications. Angew. Chem. Int. Ed. 2016, 55, 6112-6113.

(2) Garlyyev, B.; Fichtner, J.; Piqué, O.; Schneider, O.; Bandarenka, A. S.; CalleVallejo, F. Revealing the Nature of Active Sites in Electrocatalysis. Chem. Sci. 2019, 10, 80608075.

(3) Chen, J.-F.; Mao, Y.; Wang, H.-F.; Hu, P. A Simple Method to Locate the Optimal Adsorption Energy for the Best Catalysts Directly. ACS Catal. 2019, 9, 2633-2638.

(4) Bentley, C. L.; Kang, M.; Unwin, P. R. Nanoscale Surface Structure-Activity in Electrochemistry and Electrocatalysis. J. Am. Chem. Soc. 2019, 141, 2179-2193.

(5) Somorjai, G. A.; Li, Y.: Introduction to Surface Chemistry and Catalysis, John Wiley \& Sons, 2010.

(6) Buurmans, I. L. C.; Weckhuysen, B. M. Heterogeneities of Individual Catalyst Particles in Space and Time as Monitored by Spectroscopy. Nat. Chem. 2012, 4, 873-886.

(7) Taylor, H. S. A Theory of the Catalytic Surface. Proc. R. Soc. Lond. A 1925, $108,105-111$.

(8) Koper, M. T. M. Structure Sensitivity and Nanoscale Effects in Electrocatalysis. Nanoscale 2011, 3, 2054-2073.

(9) Ye, J.-Y.; Jiang, Y.-X.; Sheng, T.; Sun, S.-G. In-situ FTIR Spectroscopic Studies of Electrocatalytic Reactions and Processes. Nano Energy 2016, 29, 414-427.

(10) Li, X.; Faghri, A. Review and Advances of Direct Methanol Fuel Cells (DMFCs) Part I: Design, Fabrication, and Testing with High Concentration Methanol Solutions. J. Power Sources 2013, 226, 223-240.

(11) Badwal, S. P. S.; Giddey, S.; Kulkarni, A.; Goel, J.; Basu, S. Direct Ethanol Fuel Cells for Transport and Stationary Applications - A Comprehensive Review. Appl. Energy 2015, 145, 80-103.

(12) An, L.; Zhao, T. S.; Li, Y. S. Carbon-Neutral Sustainable Energy Technology: Direct Ethanol Fuel Cells. Renew. Sustain. Energy Rev. 2015, 50, 1462-1468.

(13) Iwasita, T. Fuel cells: Spectroscopic Studies in the Electrocatalysis of Alcohol Oxidation. J. Braz. Chem. Soc. 2002, 13, 401-409.

(14) Tiwari, J. N.; Tiwari, R. N.; Singh, G.; Kim, K. S. Recent Progress in the Development of Anode and Cathode Catalysts for Direct Methanol Fuel Cells. Nano Energy 2013, 2, 553-578.

(15) Wang, H.; Jusys, Z.; Behm, R. J. Ethanol Electrooxidation on a CarbonSupported Pt Catalyst: Reaction Kinetics and Product Yields. J. Phys. Chem. B 2004, 108, 19413-19424.

(16) Camara, G. A.; Iwasita, T. Parallel Pathways of Ethanol Oxidation: The Effect of Ethanol Concentration. J. Electroanal. Chem. 2005, 578, 315-321.

(17) Lai, S. C. S.; Koper, M. T. M. The Influence of Surface Structure on Selectivity in the Ethanol Electro-Oxidation Reaction on Platinum. J. Phys. Chem. Lett. 2010, 1, 11221125 .

(18) Colmati, F.; Tremiliosi-Filho, G.; Gonzalez, E. R.; Berna, A.; Herrero, E.; Feliu, J. M. Surface Structure Effects on the Electrochemical Oxidation of Ethanol on Platinum Single Crystal Electrodes. Faraday Discuss. 2009, 140, 379-397.

(19) Colmati, F.; Tremiliosi-Filho, G.; Gonzalez, E. R.; Berná, A.; Herrero, E.; Feliu, J. M. The Role of the Steps in the Cleavage of the C-C Bond During Ethanol Oxidation on Platinum Electrodes. Phys. Chem. Chem. Phys. 2009, 11, 9114-9123. 
(20) Barbosa, A. F. B.; Del Colle, V.; Gómez-Marín, A. M.; Angelucci, C. A.; Tremiliosi-Filho, G. Effect of the Random Defects Generated in the Surface of $\operatorname{Pt}(111)$ on the Electro-oxidation of Ethanol: An Electrochemical Study. ChemPhysChem, 2019. DOI: 10.1002/cphc.201900544.

(21) Kavanagh, R.; Cao, X.-M.; Lin, W.-F.; Hardacre, C.; Hu, P. Origin of Low $\mathrm{CO}_{2}$ Selectivity on Platinum in the Direct Ethanol Fuel Cell. Angew. Chem. Int. Ed. 2012, 51, 1572-1575.

(22) Iwasita, T. Electrocatalysis of Methanol Oxidation. Electrochim. Acta 2002, $47,3663-3674$.

(23) Housmans, T. H. M.; Wonders, A. H.; Koper, M. T. M. Structure Sensitivity of Methanol Electrooxidation Pathways on Platinum: An On-Line Electrochemical Mass Spectrometry Study. J. Phys. Chem. B 2006, 110, 10021-10031.

(24) Wang, H.; Baltruschat, H. DEMS Study on Methanol Oxidation at Poly- and Monocrystalline Platinum Electrodes: The Effect of Anion, Temperature, Surface Structure, Ru Adatom, and Potential. J. Phys. Chem. C 2007, 111, 7038-7048.

(25) Cuesta, A. At Least Three Contiguous Atoms are Necessary for CO Formation During Methanol Electrooxidation on Platinum. J. Am. Chem. Soc. 2006, 128, 13332-13333.

(26) Grozovski, V.; Climent, V.; Herrero, E.; Feliu, J. M. The Role of the Surface Structure in the Oxidation Mechanism of Methanol. J. Electroanal. Chem. 2011, 662, 43-51.

(27) Jiang, P.; Bao, X.; Salmeron, M. Catalytic Reaction Processes Revealed by Scanning Probe Microscopy. Acc. Chem. Res. 2015, 48, 1524-1531.

(28) Zhang, S.; Nguyen, L.; Liang, J.-X.; Shan, J.; Liu, J.; Frenkel, A. I.; Patlolla, A.; Huang, W.; Li, J.; Tao, F. Catalysis on Singly Dispersed Bimetallic Sites. Nat. Commun. 2015, 6, 7938 .

(29) Tao, F. F.; Ralston, W. T.; Liu, H.; Somorjai, G. A. Surface Structures of Model Metal Catalysts in Reactant Gases. J. Phys. Chem. B 2018, 122, 425-431.

(30) Chen, Q.-S.; Feliu, J. M.; Berna, A.; Climent, V.; Sun, S.-G. Kinetic Study of CO Oxidation on Step Decorated Pt(111) Vicinal Single Crystal Electrodes. Electrochim. Acta 2011, 56, 5993-6000.

(31) Chen, Q. S.; Vidal-Iglesias, F. J.; Solla-Gullón, J.; Sun, S. G.; Feliu, J. M. Role of Surface Defect Sites: From Pt Model Surfaces to Shape-Controlled Nanoparticles. Chem. Sci. 2012, 3, 136-147.

(32) Kuznetsov, A. N.; Zaikovskii, V. I.; Parmon, V. N.; Savinova, E. R. Site Blocking with Gold Adatoms as an Approach to Study Structural Effects in Electrocatalysis. Electrocatal. 2012, 3, 211-220.

(33) Kodama, K.; Jinnouchi, R.; Takahashi, N.; Murata, H.; Morimoto, Y. Activities and Stabilities of Au-Modified Stepped-Pt Single-Crystal Electrodes as Model Cathode Catalysts in Polymer Electrolyte Fuel Cells. J. Am. Chem. Soc. 2016, 138, 4194-4200.

(34) Farias, M. J. S.; Cheuquepan, W.; Camara, G. A.; Feliu, J. M. Disentangling Catalytic Activity at Terrace and Step Sites on Selectively Ru-Modified Well-Ordered Pt Surfaces Probed by CO Electro-oxidation. ACS Catal. 2016, 6, 2997-3007.

(35) Farias, M. J. S.; Cheuquepán, W.; Tanaka, A. A.; Feliu, J. M. Nonuniform Synergistic Effect of $\mathrm{Sn}$ and $\mathrm{Ru}$ in Site-Specific Catalytic Activity of $\mathrm{Pt}$ at Bimetallic Surfaces toward CO Electro-oxidation. ACS Catal. 2017, 7, 3434-3445.

(36) Pfisterer, J. H. K.; Liang, Y.; Schneider, O.; Bandarenka, A. S. Direct Instrumental Identification of Catalytically Active Surface Sites. Nat. 2017, 549, 74-77.

(37) Ford, L. P.; Nigg, H. L.; Blowers, P.; Masel, R. I. The Role of Step Atom Density on the Binding and Reaction of Surface Species. J. Catal. 1998, 179, 163-170. 
(38) Farias, M. J. S.; Cheuquepán, W.; Tanaka, A. A.; Feliu, J. M. Unraveling the Nature of Active Sites in Ethanol Electro-oxidation by Site-Specific Marking of a Pt Catalyst with Isotope-Labeled ${ }^{13}$ CO. J. Phys. Chem. Lett. 2018, 9, 1206-1210.

(39) Lang, B.; Joyner, R. W.; Somorjai, G. A. Low Energy Electron Diffraction Studies of High Index Crystal Surfaces of Platinum. Surf. Sci. 1972, 30, 440-453.

(40) Clavilier, J.; Armand, D.; Sun, S. G.; Petit, M. Electrochemical Adsorption Behaviour of Platinum Stepped Surfaces in Sulphuric Acid Solutions. J. Electroanal. Chem. 1986, 205, 267-277.

(41) Iwasita, T.; Nart, F. C. In Situ Infrared Spectroscopy at Electrochemical Interfaces. Prog. Surf. Sci. 1997, 55, 271-340.

(42) Gómez, R.; Climent, V.; Feliu, J. M.; Weaver, M. J. Dependence of the Potential of Zero Charge of Stepped Platinum (111) Electrodes on the Oriented Step-Edge Density: Electrochemical Implications and Comparison with Work Function Behavior. J. Phys. Chem. B 2000, 104, 597-605.

(43) Climent, V.; Feliu, J. M.: Surface Electrochemistry with Pt Single-Crystal Electrodes. In Advances in Electrochemical Science and Engineering, Wiley-VCH Verlag GmbH \& Co. KGaA, 2017; pp 1-57.

(44) Clavilier, J.; El Achi, K.; Rodes, A. In Situ Probing of Step and Terrace Sites on $\operatorname{Pt}(\mathrm{s})-[n(111) \times(111)]$ Electrodes. Chem. Phys. 1990, 141, 1-14.

(45) Herrero, E.; Climent, V.; Feliu, J. M. On the Different Adsorption Behavior of Bismuth, Sulfur, Selenium and Tellurium on a $\mathrm{Pt}(775)$ Stepped Surface. Electrochem. Commun. 2000, 2, 636-640.

(46) Creighan, S. C.; Mukerji, R. J.; Bolina, A. S.; Lewis, D. W.; Brown, W. A. The Adsorption of CO on the Stepped Pt\{211\} Surface: A Comparison of Theory and Experiment. Catal. Lett. 2003, 88, 39-45.

(47) Tränkenschuh, B.; Papp, C.; Fuhrmann, T.; Denecke, R.; Steinrück, H. P. The Dissimilar Twins - A Comparative, Site-Selective in situ Study of CO Adsorption and Desorption on $\mathrm{Pt}(322)$ and $\mathrm{Pt}(355)$. Surf. Sci. 2007, 601, 1108-1117.

(48) Farias, M. J. S.; Mello, G. A. B.; Tanaka, A. A.; Feliu, J. M. Site-Specific Catalytic Activity of Model Platinum Surfaces in Different Electrolytic Environments as Monitored by the CO Oxidation Reaction. J. Catal. 2017, 345, 216-227.

(49) Kim, C. S.; Korzeniewski, C. Vibrational Coupling as a Probe of Adsorption at Different Structural Sites on a Stepped Single-Crystal Electrode. Anal. Chem. 1997, 69, 23492353.

(50) Ferre-Vilaplana, A.; Buso-Rogero, C.; Feliu, J. M.; Herrero, E. Cleavage of the $\mathrm{C}-\mathrm{C}$ Bond in the Ethanol Oxidation Reaction on Platinum. Insight from Experiments and Calculations. J. Phys. Chem. C 2016, 120, 11590-11597.

(51) Tomaschun, G.; Klüner, T. Methanol Oxidation on the $\operatorname{Pt}(321)$ Surface: A Theoretical Approach on the Role of Surface Morphology and Surface Coverage Effects. Phys. Chem. Chem. Phys. 2019, 21, 18227-18239.

(52) Batista, E. A.; Iwasita, T. Adsorbed Intermediates of Formaldehyde Oxidation and their Role in the Reaction Mechanism. Langmuir 2006, 22, 7912-7916.

(53) Holden Norman, E.; Coplen Tyler, B.; Böhlke John, K.; Tarbox Lauren, V.; Benefield, J.; de Laeter John, R.; Mahaffy Peter, G.; O’Connor, G.; Roth, E.; Tepper Dorothy, H.; Walczyk, T.; Wieser Michael, E.; Yoneda, S.: IUPAC Periodic Table of the Elements and Isotopes (IPTEI) for the Education Community (IUPAC Technical Report). In Pure Appl. Chem. 2018; Vol. 90; pp 1833. 
(54) Martins, C. A.; Fernández, P. S.; Troiani, H. E.; Martins, M. E.; Camara, G. A. Ethanol vs. Glycerol: Understanding The Lack of Correlation Between the Oxidation Currents and the Production of $\mathrm{CO}_{2}$ on Pt Nanoparticles. J. Electroanal. Chem. 2014, 717-718, 231236.

(55) Iwasita, T.; Xia, X.; Herrero, E.; Liess, H. D. Early Stages During the Oxidation of $\mathrm{HCOOH}$ on Single-Crystal Pt Electrodes as Characterized by Infrared Spectroscopy. Langmuir 1996, 12, 4260-4265.

(56) Persson, B. N. J.; Ryberg, R. Vibrational Interaction Between Molecules Adsorbed on a Metal Surface: The Dipole-Dipole Interaction. Phys. Rev. B 1981, 24, 69546970.

(57) Kim, C. S.; Tornquist, W. J.; Korzeniewski, C. Site-Dependent Vibrational Coupling of CO Adsorbates on Well-Defined Step and Terrace Sites of Monocrystalline Platinum: Mixed-Isotope Studies at $\mathrm{Pt}(335)$ and $\mathrm{Pt}(111)$ in the Aqueous Electrochemical Environment. J. Chem. Phys. 1994, 101, 9113-9121.

(58) Lide, D. L. CRC Handbook of Chemistry and Physics, 87th ed.; CRC Press: Boca Raton, FL, 2006-2007.

(59) Leung, L.-W. H.; Chang, S.-C.; Weaver, M. J. Real-Time FTIR Spectroscopy as an Electrochemical Mechanistic Probe: Electrooxidation of Ethanol and Related Species on Well-Defined Pt (111) Surfaces. J. Electroanal. Chem. 1989, 266, 317-336.

(60) Iwasita, T.; Camara, G. A.: Contributions of External Reflection Infrared Spectroscopy to Study the Oxidation of Small Organic Molecules. In In-situ Spectroscopic Studies of Adsorption at the Electrode and Electrocatalysis, 2007; pp 33-61.

(61) Del Colle, V.; Souza-Garcia, J.; Tremiliosi-Filho, G.; Herrero, E.; Feliu, J. M. Electrochemical and Spectroscopic Studies of Ethanol Oxidation on Pt Stepped Surfaces Modified by Tin Adatoms. Phys. Chem. Chem. Phys. 2011, 13, 12163-12172.

(62) Smoluchowski, R. Anisotropy of the Electronic Work Function of Metals. Phys. Rev. 1941, 60, 661-674.

(63) Sakong, S.; Groß, A. The Importance of the Electrochemical Environment in the Electro-Oxidation of Methanol on Pt(111). ACS Catal. 2016, 6, 5575-5586.

(64) Lopes, P. P.; Strmcnik, D.; Jirkovsky, J. S.; Connell, J. G.; Stamenkovic, V.; Markovic, N. Double Layer Effects in Electrocatalysis: The Oxygen Reduction Reaction and Ethanol Oxidation Reaction on $\mathrm{Au}(111), \operatorname{Pt}(111)$ and $\operatorname{Ir}(111)$ in Alkaline Media Containing $\mathrm{Na}$ and Li Cations. Catal. Today 2016, 262, 41-47. 


\section{Figures}

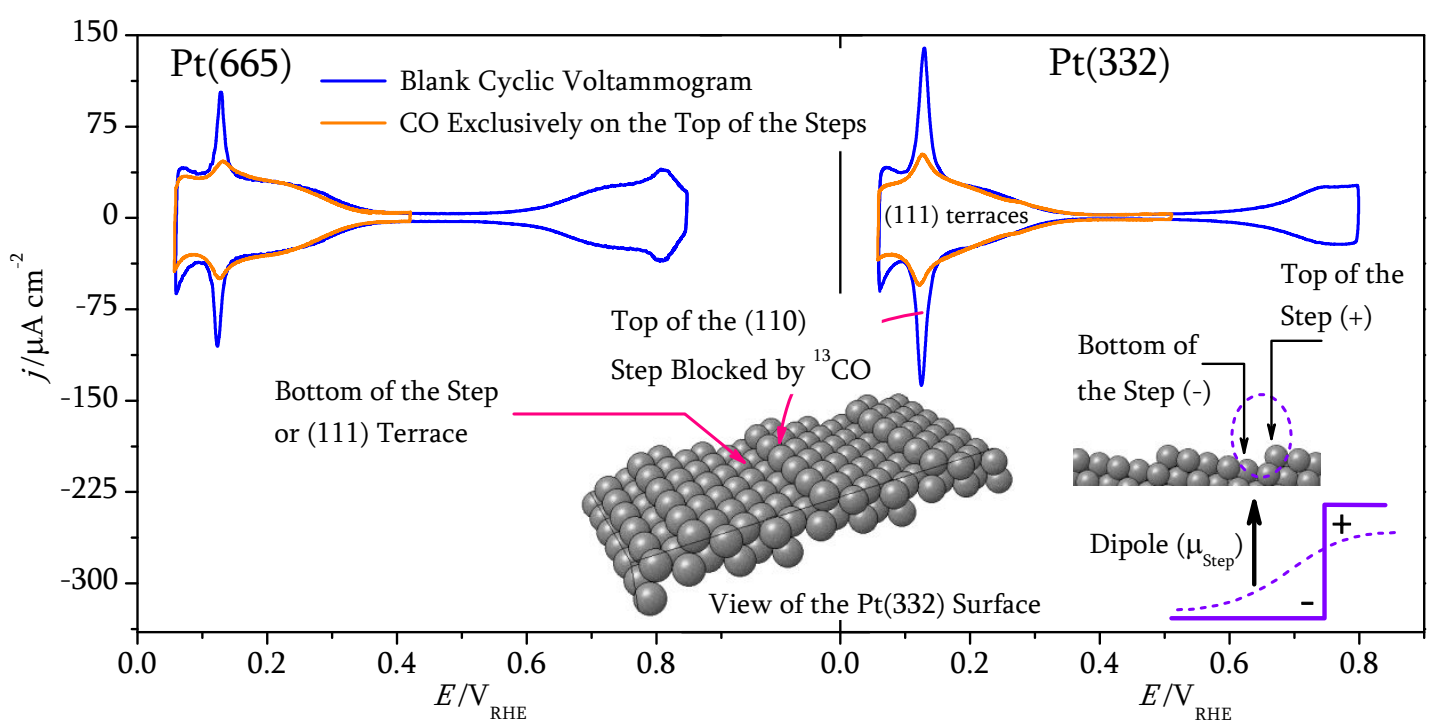

Figure 1. Cyclic voltammograms of the $\mathrm{Pt}(332)$ and $\mathrm{Pt}(665)$ crystals in the presence of $0.1 \mathrm{M}$ $\mathrm{HClO}_{4}$, at $50 \mathrm{mV} \mathrm{s}^{-1}$. Black line: blank voltammogram; orange line: ${ }^{13} \mathrm{CO}$ exclusively on the top of the (110) steps. The data include a hard model (drawn here: http://surfexp.fhiberlin.mpg.de/) of a crystal surface. The row of atoms at the bottom of the steps is part of the steps. 

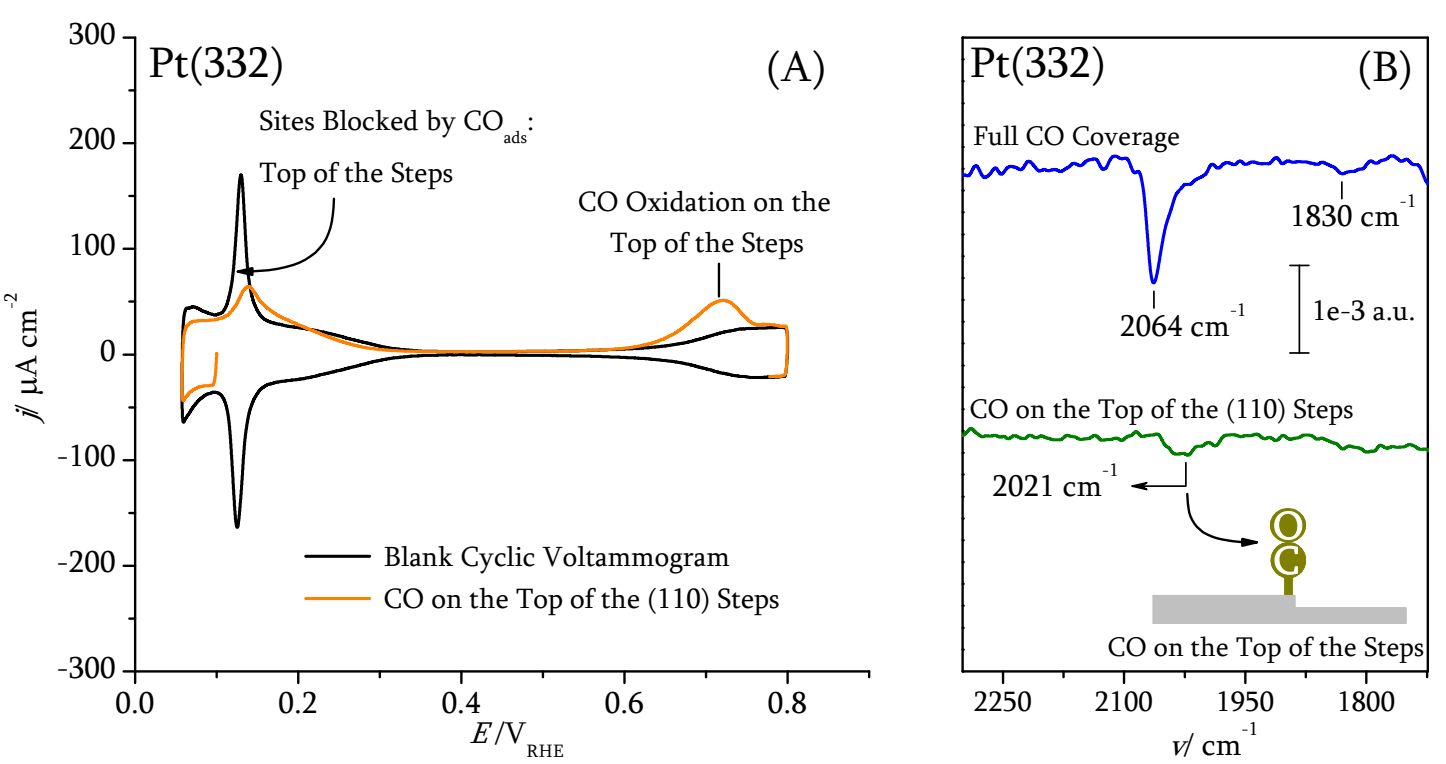

Figure 2. (A): Cyclic voltammetry for oxidation of CO only on the top of the (110) steps of $\mathrm{Pt}(332)$ in $0.1 \mathrm{M} \mathrm{HClO}_{4}$ electrolyte solution (orange line). The data shown by the black line refer to the blank cyclic voltammetry. Data recorded at a potential scan rate of $50 \mathrm{mV} \mathrm{s}^{-1}$. (B): In situ FTIR spectra at $0.200 \mathrm{~V}_{\mathrm{RHE}}$ of adsorbed ${ }^{12} \mathrm{CO}$ on a $\mathrm{Pt}(332)$ surface in $0.1 \mathrm{M} \mathrm{HClO}_{4}$, for $\mathrm{CO}$ at full coverage (blue line) and CO only on the top of the steps (olive line). The reference spectra were acquired at $0.800 \mathrm{~V}_{\mathrm{RHE}}$. 

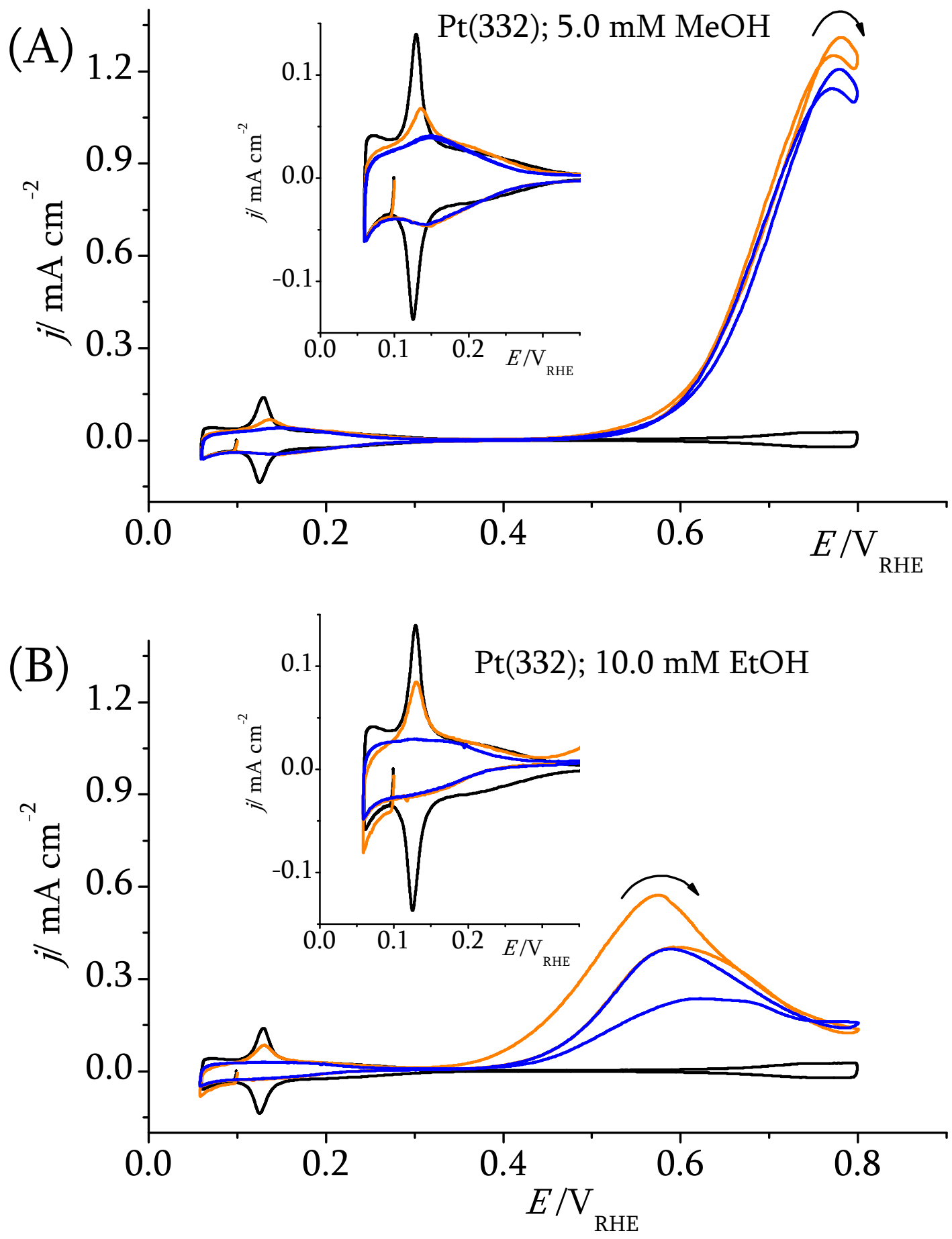

Figure 3. Two consecutive voltammetric cycles for the electro-oxidation of methanol (5.0 $\mathrm{mM})$ and ethanol $(10.0 \mathrm{mM})$ on a stepped $\mathrm{Pt}(332)$ single crystal in $0.1 \mathrm{M} \mathrm{HClO}_{4}$ electrolyte. Orange line: first potentiodynamic cycle; blue line: second potentiodynamic cycle; black line: blank voltammogram. Data recorded at a scan rate of $50 \mathrm{mV} \mathrm{s}^{-1}$. 

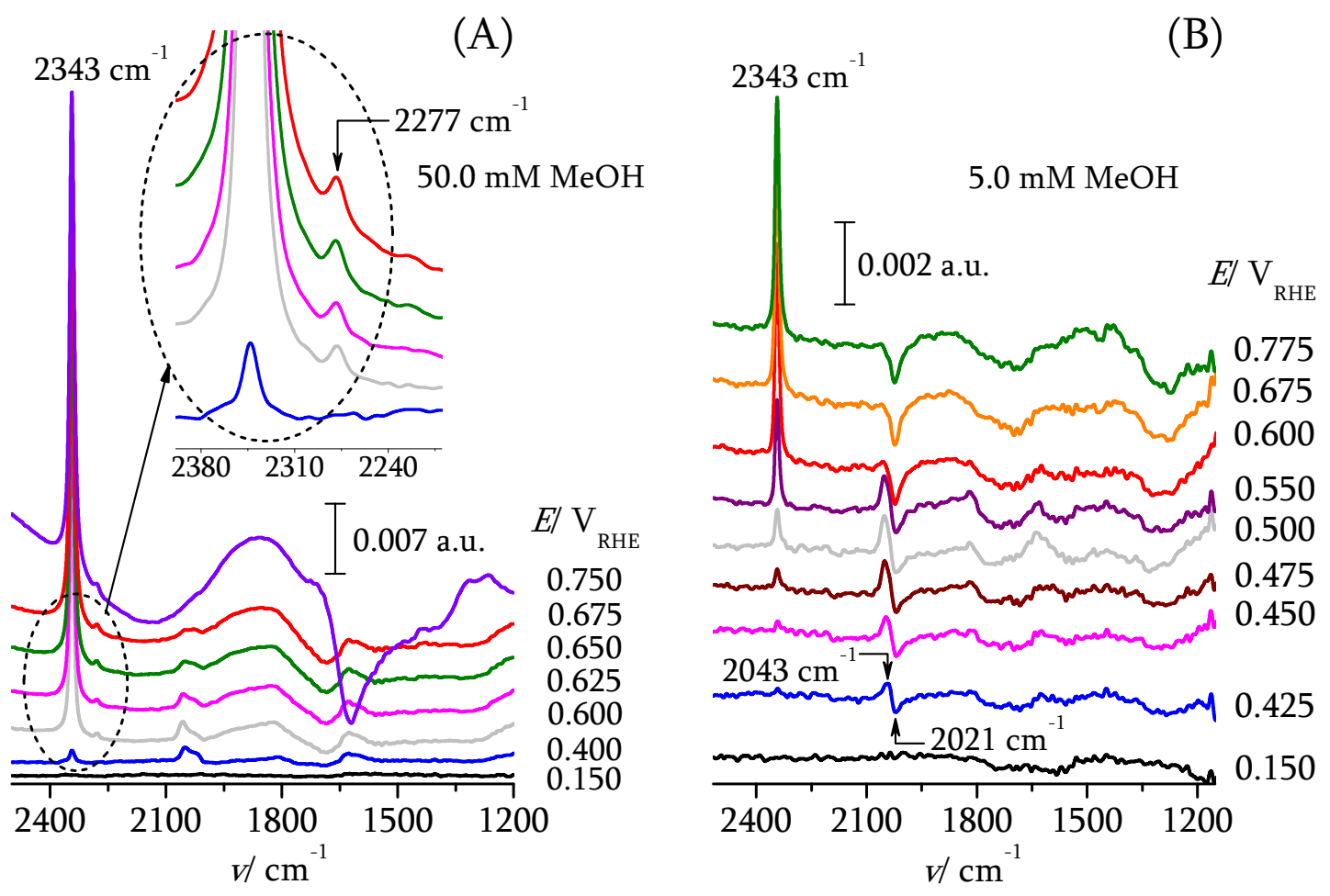

Figure 4. Spectra for electro-oxidation of methanol on a $\mathrm{Pt}(332)$ stepped single crystal in 0.1 $\mathrm{M} \mathrm{HClO}_{4}$. (A) $50.0 \mathrm{mM}$ methanol; (B) $5.0 \mathrm{mM}$ methanol. The data show the influence of the concentration of common methanol on the magnitude of the band for ${ }^{13} \mathrm{CO}_{2}$. The series of spectra (200 interferograms at resolution of $8 \mathrm{~cm}^{-1}$ ) was acquired from 0.050 to $0.800 \mathrm{~V}_{\mathrm{RHE}}$, in intervals of $25 \mathrm{mV}$ (only some selected spectra are shown). The reference spectrum was acquired at $0.100 \mathrm{~V}_{\mathrm{RHE}}$. 


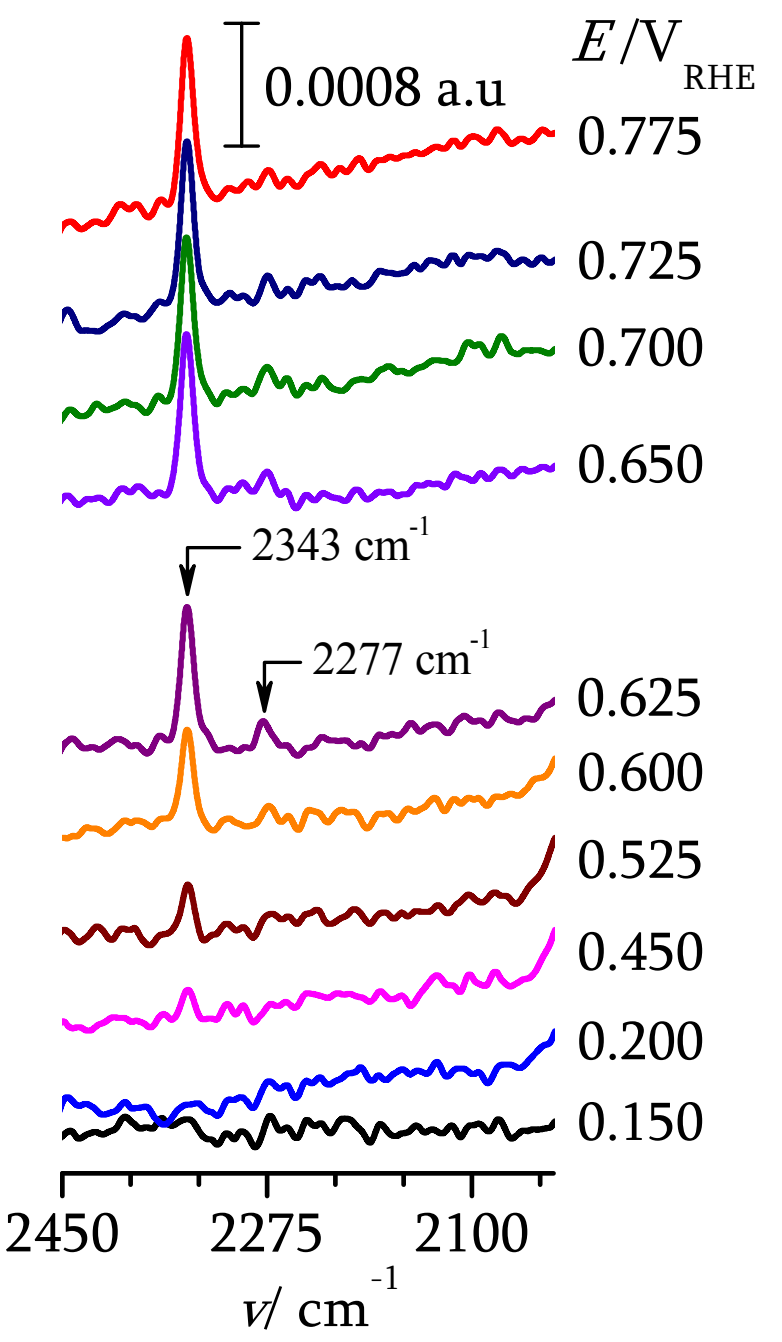

Figure 5. Spectra for the electro-oxidation of methanol $(1.0 \mathrm{mM})$ on a $\operatorname{Pt}(332)$ stepped surface with the (110) steps previously and selectively decorated with ${ }^{13} \mathrm{CO}_{\mathrm{ads}}$. The series of spectra (200 interferograms at resolution of $8 \mathrm{~cm}^{-1}$ ) was acquired from 0.050 to $0.800 \mathrm{~V}_{\mathrm{RHE}}$, in intervals of $25 \mathrm{mV}$ (only some selected spectra are shown). The reference spectrum was acquired at $0.100 \mathrm{~V}_{\mathrm{RHE}}$. 


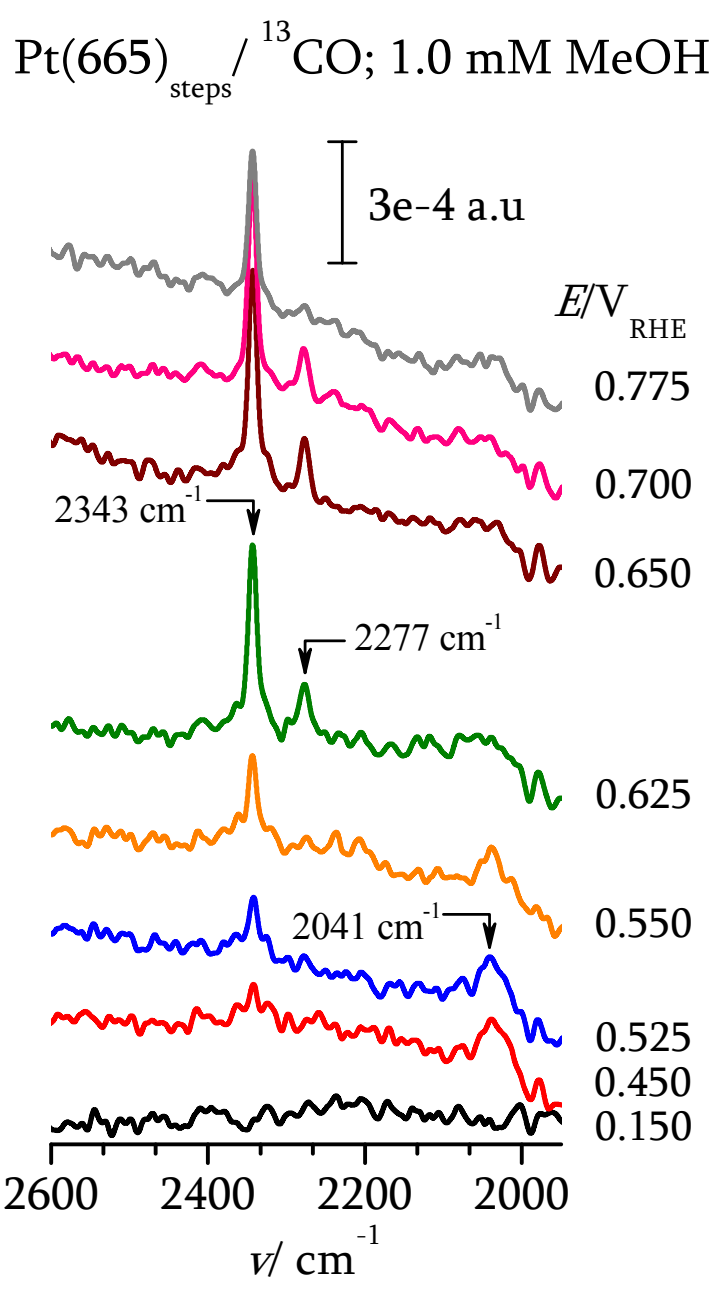

Figure 6. Spectra for the electro-oxidation of methanol $(1.0 \mathrm{mM})$ on a $\operatorname{Pt}(665)$ stepped surface with the (110) steps previously and selectively decorated with ${ }^{13} \mathrm{CO}_{\mathrm{ads}}$. The series of spectra (200 interferograms at resolution of $8 \mathrm{~cm}^{-1}$ ) was acquired from 0.050 to $0.800 \mathrm{~V}_{\mathrm{RHE}}$, in intervals of $25 \mathrm{mV}$ (only some selected spectra are shown). The reference spectrum was acquired at $0.100 \mathrm{~V}_{\mathrm{RHE}}$. 


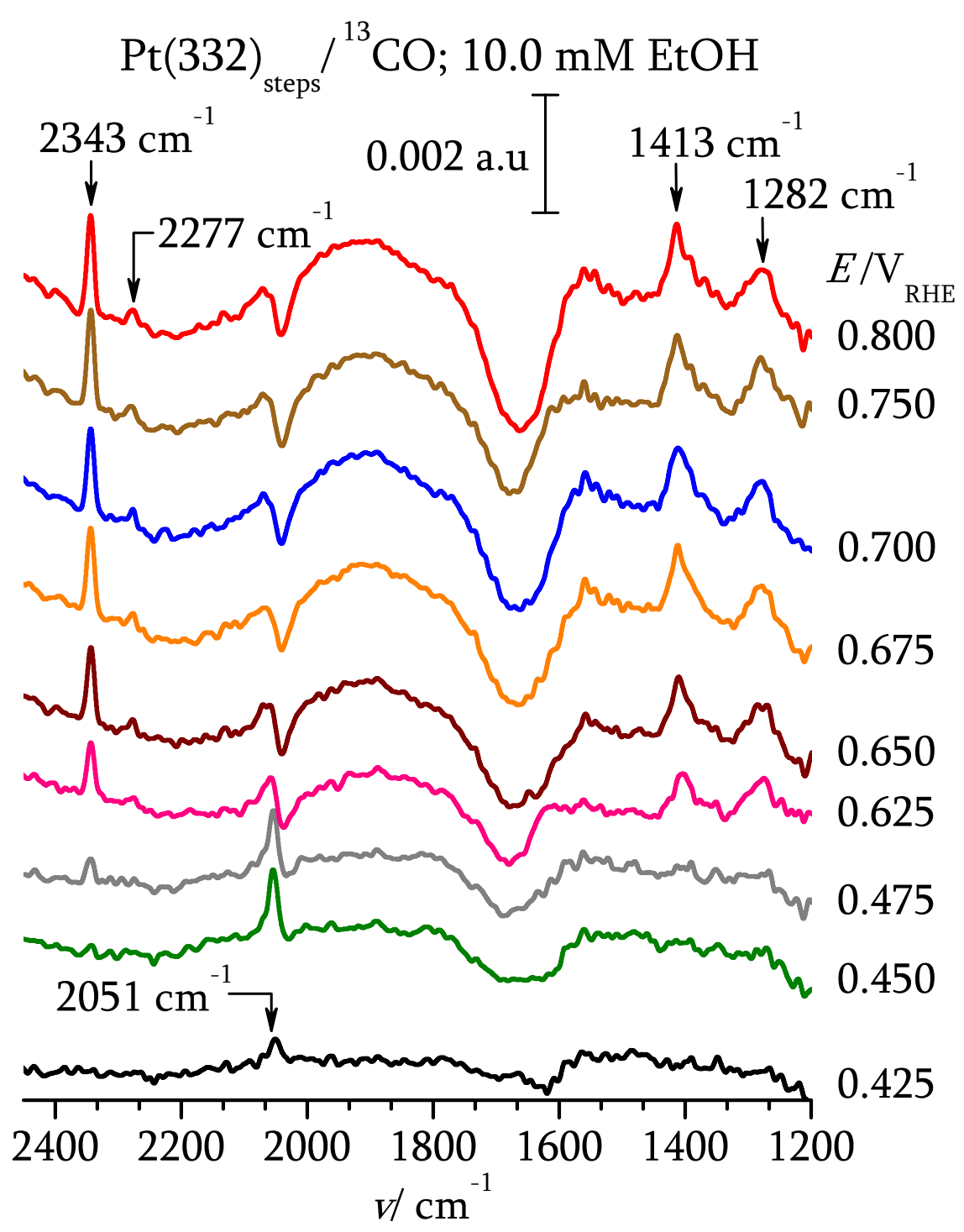

Figure 7. Spectra for the electro-oxidation of ethanol $(10.0 \mathrm{mM})$ on a $\operatorname{Pt}(332)$ stepped surface with the (110) steps previously and selectively decorated with ${ }^{13} \mathrm{CO}_{\text {ads. }}$ The series of spectra (200 interferograms at resolution of $8 \mathrm{~cm}^{-1}$ ) was acquired from 0.050 to $0.800 \mathrm{~V}_{\mathrm{RHE}}$, in intervals of $25 \mathrm{mV}$ (only some selected spectra are shown). The reference spectrum was acquired at $0.400 \mathrm{~V}_{\mathrm{RHE}}$. 


\section{Graphical Abstract}

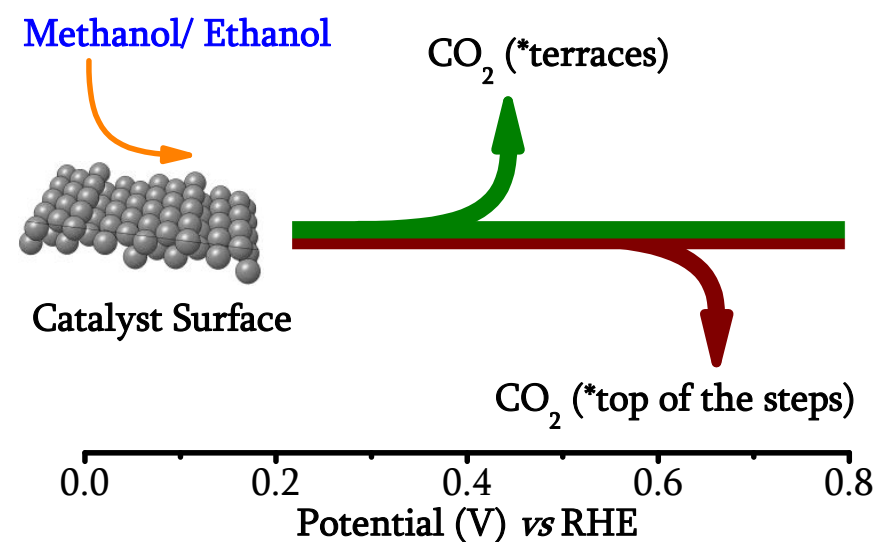

